
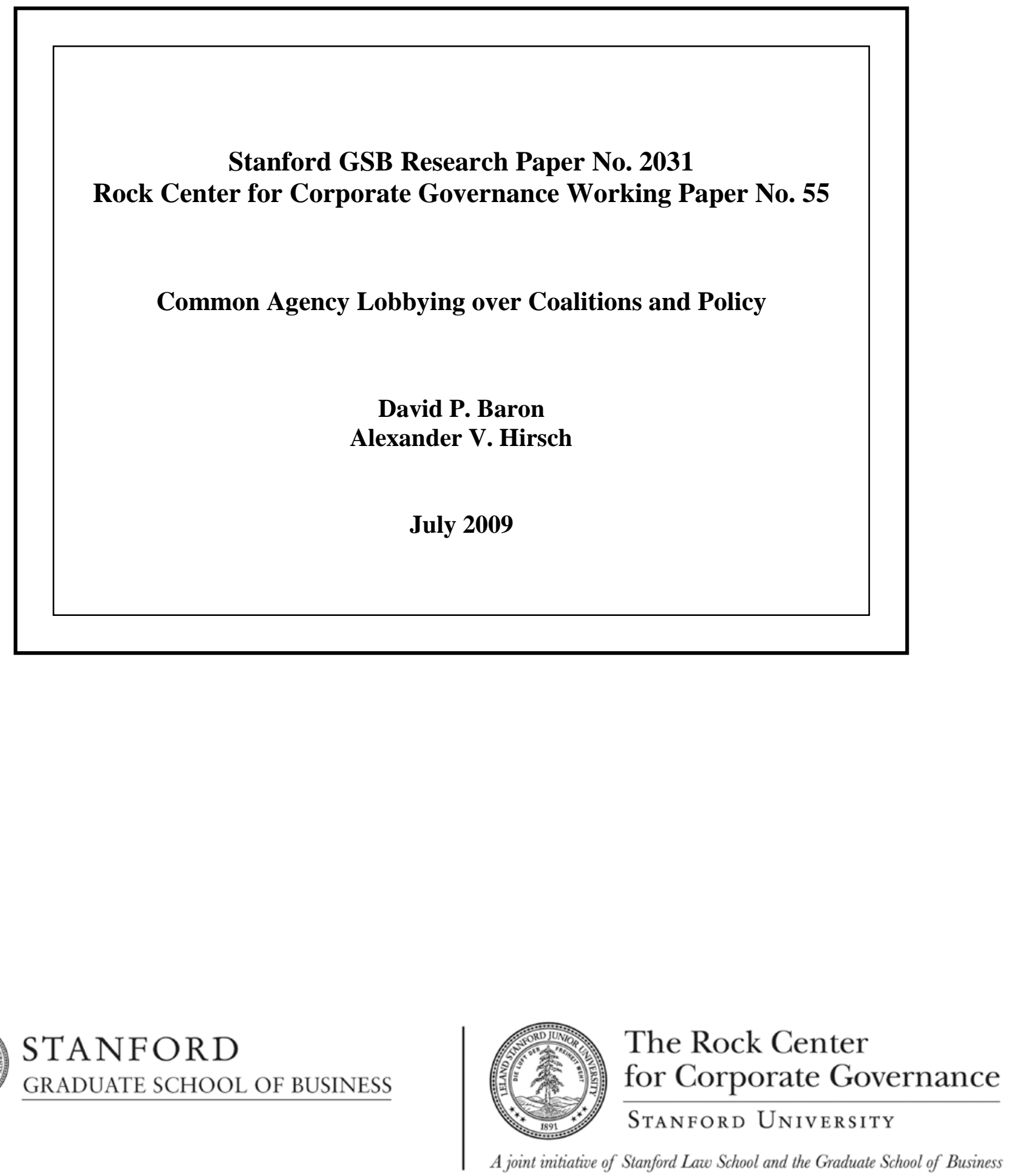


\title{
Common Agency Lobbying over Coalitions and Policy
}

\author{
David P. Baron and Alexander V. Hirsch *
}

July 12, 2009

\begin{abstract}
This paper presents a theory of common agency lobbying in which policy-interested lobbies can first influence the choice of a governing coalition and then influence the legislative bargaining over policies. Equilibria can involve active lobbying at both stages of the governing process. Contributions can also be made to defeat a policy proposal, and although those contributions are never successful they can influence coalition choice. The equilibrium policy in the legislative bargaining stage is efficient given the coalition selected, but the equilibrium coalition need not be efficient. Lobbying can also lead to the preservation of the status quo and lobby-induced gridlock. An example is presented to identify the multiplicity of equilibria and provide a full characterization of an equilibrium.
\end{abstract}

\footnotetext{
${ }^{*}$ Graduate School of Business, Stanford University, 518 Memorial Way, Stanford, CA 94305. We thank John Patty for comments on an earlier version of the paper.
} 


\section{Introduction}

Interest groups and their lobbies attempt to influence policy and can do so both by lobbying the government and by influencing the choice of the governing coalition. The extent of their influence depends not only on their preferences and resources but also on the preferences of government officeholders and the characteristics of institutions and their procedures. This paper identifies the influence of lobbies relative to political officeholders in the context of a majority-rule institution in which coalitions choose policies. The lobbies provide politically-valuable resources to officeholders to influence coalition formation and once the coalition has formed to influence its policy choice. The institutional model takes representation as given and focuses on parties or legislators forming coalitions and choosing policies in the presence of interest groups that can influence both. That is, coalitions and policies are chosen with an eye to the interest groups that support the officeholders or their parties.

The approach to studying influence is based on the common agency lobbying model introduced by Grossman and Helpman (1994) using the theory of menu auctions developed by Bernheim and Whinston (1986a)(1986b). Our model extends the common agency lobbying framework in three ways. First, it includes a privileged alternative, the status quo, that must be beaten by any other alternative. Second, lobbies can use their influence to defeat a coalition and its policy and thereby preserve the status quo. Third, the policy is chosen by majority rule where there is a collection of decisive coalitions. To incorporate majority rule into the menu auctions framework, we use a legislative bargaining game.

The common agency lobbying model assumes that utility is transferable between lobbies and government, and we extend this assumption to allow transfers among legislators, who have opportunities to allocate offices such as ministries as well as to exchange favors, votes on other measures, electoral resources, pork, and officeholding benefits. A general treatment of common agency lobbying and majority rule institutions is extremely complex, and we make three simplifying assumptions. First, we assume that governing involves two stages: first a coalition is selected, and then the coalition members bargain over policy and officeholding benefits. As applied to government formation in a parliamentary system, a formateur is selected to identify a proto-coalition, and once identified the members of the proto-coalition bargain over policy, the allocation of ministries, and officeholding benefits. Once an agreement is reached, the coalition and its policy are subject

to an investiture vote. Second, we assume that lobbies make contribution offers in two stages paralleling the stages of the governing process; i.e., offers are first made in the coalition formation stage to influence proto-coalition selection, and then in the legislative stage contributions are made to influence policy choice. 
Third, as in proto-coalition bargaining we assume that once a coalition has been selected, every member of the coalition must agree to the legislative bargain.

In the model, lobbies are strictly policy motivated and have no primitive preferences over coalitions. Anticipation of future lobbying over policy in the legislative bargaining stage, however, generates induced preferences of lobbies over the possible governing coalitions. These induced preferences arise naturally from combining common agency with legislative bargaining and form the basis for lobbying in the coalition selection stage. Once a coalition has been selected the resulting policy maximizes the aggregate utility of the coalition members and the lobbies when a truthfulness refinement is used. The equilibrium coalition, however, need not be the one that yields the greatest aggregate utility, since contributions in favor of the status quo can affect the selection of a coalition. The formateur faces a tradeoff, since choosing a larger coalition yields a larger surplus to be divided among the coalition members but also reduces her bargaining power within the proto-coalition.

Some properties of the equilibria are inherited from the common agency approach. With truthful contribution schedules policies maximize the aggregate utility of the coalition members and the lobbies, and this implies that the equilibrium policies can, for example, be outside the Pareto set of the legislators due to the influence of lobbies. In addition, lobbying can be counteractive, where the influence of the lobbies is offsetting, resulting in little influence on policy in the legislative bargaining and leaving the lobbies worse off than if lobbying were prohibited.

Lobbying in a majority-rule institution, however, also exhibits properties that contrast with the GrossmanHelpman model. First, total equilibrium contributions can be in excess of the contributions necessary to maintain influence in the legislative bargaining subgame commencing after the choice of a coalition. That is, lobbies may "bid up" their contributions to influence the formateur's choice of a coalition. Second, equilibria can involve contributions to defeat the policy proposal and preserve the status quo. These contributions never succeed in causing the coalition to fail, and the coalition-efficient policy prevails. However, anticipation of lobbying in favor of the status quo can result in the choice of an inefficient coalition by the formateur, in the sense that the chosen coalition need not be the one that maximizes aggregate policy utility of the lobbies and the coalition members. When the status quo is centrally located relative to the preferences of legislators and lobbies, anticipation of lobbying in favor of the status quo can result in the failure to propose a governing coalition, in which case the status quo prevails. Gridlock thus can result from lobbying. Lobbying can also induce surplus coalitions where in the absence of lobbying only minimal winning coalitions would be chosen. Third, in the legislative bargaining the preferences of the coalition members and the lobbies receive equal weight in the policy choice, but in the coalition selection the surplus of the coalition members receives only a fraction, determined by the size of the coalition, of the weight of the lobbies' preferences over coalitions. 
Lobbies have more influence relative to legislators on coalition selection than on policy choice because power is dispersed in the legislative bargaining and concentrated in a single formateur in coalition selection.

Helpman and Persson (2001) provide a model that extends the common agency approach to majority rule institutions. They study an institution in which each legislator is paired with a lobby that can offer contributions only to that legislator. They find that when the policy is distributive and legislators care only about the contributions they receive from lobbyists, the proposer captures all the surplus and contributions are zero in equilibrium. In our model, equilibrium contributions are not zero when legislators care only about the contributions they receive. In Helpman and Persson, when legislators also care about the welfare of their constituents in addition to contributions, the proposer in effect extracts as much as possible from one lobbyist in exchange for a distributive allocation and selects the lobbyist that is willing to pay the most. Lobbying contributions are positive in equilibrium but made only by the lobbyist aligned with the proposer's coalition partner. In our model lobbies are unrestricted with respect to which legislators they can contribute, so lobbies compete directly. This affects distribution as well as policy and coalition choice.

One class of majority-rule lobbying models departs from the common agency approach by assuming that the voting agenda is exogenous and that legislators care about how they vote, rather than the policy outcome. These models thus identify the effect of lobbying on coalition formation, but say little about their influence on policy since the agenda is binary and fixed. Groseclose and Snyder (1996) show that supermajorities can result when one lobby prices the other out of the lobbying. Whereas Groseclose and Snyder consider only one round of lobby offers, Dekel, Jackson, and Wolinsky (2007) consider unlimited alternating offers where the lobbyists are budget constrained or unconstrained.

Baron (2006) considers a lobbying model in which a three-person legislature chooses between two exogenouslygiven alternatives, each of which is preferred by a lobby. The lobbies make offers sequentially and between offers the legislators play a bargaining game. The equilibria depend on the utility differences of the lobbies for the two alternatives. When those differences are small for both lobbies, minimal winning coalitions are formed and contributions are at the minimum required to support the winning coalition. When those differences are large for both lobbyists, the lobbies bid up the price of a vote and supermajorities can result. In the model presented here policy is endogenous and competition among the lobbies can also result in bidding up the contributions and in supermajorities.

The common agency, majority-rule model presented here is related to work by Prat and Rustichini (2003) and Segal (1999). In the terminology of Prat and Rustichini, the model is a multi-principal, multi-agent version of a game played through agents. The offers by lobbies in the model are more general than considered in their Section 6.4, and the payoffs to the officeholders depend on the outcome rather than their actions. Segal (1999) considered a single-principal, multi-agent model and showed that efficiency is not attained when 
there are externalities among the agents. Both sets of authors focus on the efficiency of outcomes.

In our model, policies are not necessarily efficient in the strong sense of maximizing the joint utility of all lobbies and legislators. As in a legislative bargaining model absent lobbying, the formateur may prefer to exclude legislators who are advantaged in the legislative bargaining. When this occurs, the governing coalition imposes a negative externality on non-coalition members through its choice of policy. Strong efficiency only obtains when the formateur selects a consensus coalition, which arises in our model when all legislators other than the formateur are strongly disadvantaged by the status quo. Our focus is less on efficiency and more on characterizing the influence of lobbies on policy choice and coalition selection.

The equilibria characterized for our model are not unique. The truthfulness refinement of Bernheim and Whinston is used at each lobbying stage but still leaves a multiplicity of equilibria. The multiplicity results because of alternative ways in which the lobbies can support the policy choice and selection of a coalition and because of contributions in support of the status quo. These affect distribution and also affect coalition and hence policy choice. Examples are presented to illustrate both the equilibrium policies and coalitions and how the equilibria are characterized. Identifying the equilibrium coalition and its policy is relatively simple, whereas determining the equilibrium contributions and payoffs of the players is relatively complex.

The next section introduces the model, and Section 3 characterizes the equilibrium lobbying directed at influencing legislative bargaining and the equilibrium lobbying directed at influencing the choice of a coalition. Sections 4 applies the truthfulness refinement. Examples are presented in Section 5, and conclusions are offered in the final section.

\section{The Legislative Bargaining and Lobbying Game}

\subsection{The Model}

The players include a set $P=\{1, \ldots, N\}, N \geq 3$, of legislators or parties and a set $L=\{1, \ldots, \bar{L}\}$ of lobbies. The governing process has two stages. In the coalition selection stage an exogenously-selected formateur $f$

publicly identifies a coalition $A \in D^{f} \cup \emptyset$, where $D^{f}$ is the set of decisive coalitions that include the formateur and $\emptyset$ denotes not forming a coalition. For example with majority rule $D^{f}=\left\{A \subset P:|A| \geq \frac{N+1}{2}, f \in A\right\}$. If the formateur chooses $\emptyset$, the game ends and the status quo policy $q$ continues. If a coalition is selected, the legislative bargaining stage commences, and any agreement reached must be approved by the legislature. The coalition thus is to be thought of as a proto-coalition within which the coalition members bargain.

In the legislative bargaining stage the coalition members bargain over policy and officeholding benefits. The coalition selects a platform consisting of a policy $x$ chosen from a compact policy space $X \subset \Re^{M}$, and a vector $s$ of transfers among the members of the coalition $A$ where $s=\left(s_{1}, \ldots, s_{N}\right) \in S=\left\{\Re^{N} \mid \sum_{j \in P} s_{j}=\right.$ 
$\bar{S} \geq 0$ and $s_{k}=0$ for $\left.k \notin A\right\}$. Legislator $i$ 's policy preferences are represented by $\alpha_{i} u_{i}(x)$, where $\alpha_{i} \geq 0$ and $u_{i}(x)$ is differentiable and strictly concave with a maximum on the interior of $X$. For simplicity we assume that the coalition cannot choose transfers to or from legislators outside the coalition, which in effect gives each legislator individual veto power over his own transfer.

We follow the proto-coalition literature, discussed below, in assuming that unanimity within the coalition is required for successful bargaining. Should any coalition member reject the proposed platform, the status quo policy $q \in X$ remains in place and the proposed transfers are called off. If the bargain is accepted by every member of the proto-coalition, it is assumed to be successfully implemented by the legislature since the proto-coalition is decisive. This assumption could, for example, be a consequence of a formal investiture vote following the bargaining in which the coalition can credibly commit to call off the bargain should any individual member renege.

The lobbying tracks this process. Lobbies first attempt to influence the choice of a coalition, and once the coalition has been chosen, they attempt to influence the bargaining over platforms. We assume lobbies have preferences over policy but do not have primitive preferences over the coalition or $s$, the transfers and allocation of the officeholding benefits. ${ }^{1}$ Let lobby $\ell$ 's policy preferences be represented by a differentiable, strictly concave utility function $v_{\ell}(x)$ that is assumed to have a maximum on the interior of $X$.

A number of protocols for legislative bargaining could be used, and to simplify exposition we assume a simple random recognition, take-it-or-leave-it bargaining game. This game yields identical expected utilities to those of the unique Markov Perfect Equilibrium of an infinite horizon, sequential bargaining game with random recognition and an exogenous probability $r \in(0,1)$ of bargaining breakdown. In these bargaining protocols the identity of the proposer is assumed to be unobservable to the lobbies, and a platform proposed in a bargaining round is observable only when it has been accepted and the bargaining has ended.

In the legislative bargaining a proposer is first randomly recognized from the proto-coalition $A$ to offer a platform $(x, s)$, and we assume that each legislator is recognized with probability $\frac{1}{|A|}$. The identity of the proposer in the bargaining may or may not be the same as the identity of the formateur. After a platform is proposed, each legislator in the coalition chooses whether to accept or reject the bargain. Let $z_{j}=\{0,1\}$ denote the acceptance strategy of a coalition legislator, where $z_{j}=1$ denotes acceptance. If any legislator in the coalition rejects the bargain, all transfers are called off and the status quo $q$ prevails. ${ }^{2}$ This is equivalent

\footnotetext{
${ }^{1}$ Such preferences could be included in the model, but they would detract from the focus on how preferences over coalitions arise endogenously.

${ }^{2}$ In the sequential bargaining protocol a member of the proto-coalition is randomly recognized to propose a platform and if accepted by all members, the bargaining ends. If the platform is rejected by a member of $A$, the bargaining ends with probability $r$ and the status quo prevails. With probability $1-r$ a member is randomly recognized to propose a platform, and so on.
} 
to a final vote on the coalition $A$ and its agreed policy, where all members of $A$ are required to vote yes or else the coalition formation attempt fails.

In the bargaining, an $s_{i} \geq(<) 0$ represents an increase (decrease) in $i$ 's office-holding benefits from a transfer from (to) one or more of the other legislators. The officeholding benefits may be thought of as grease that helps seal a bargain. These transfers could take the form of the allocation of ministries and other offices, vote trades on other issues, policy favors, constituency-specific entitlements such as agricultural commodity price supports, the redistribution of quasi-entitlements such as appointments or patronage, forgoing pork in the future, or the transfer of electoral resources. Baron and Diermeier (2001, p. 935) provided examples of officeholding benefits in parliamentary democracies:

These benefits include jobs for party stalwarts, board seats on public companies or the national television system, and transfers to interest groups and party foundations. Again, consider Germany; all the major parties (as well as interest groups like churches and labor unions) occupy seats on the supervisory boards of the national television system and major corporations (such as Volkswagen). Moreover, each major party receives substantial amounts of public money for its research and education foundations. Similar arrangements are common in many other parliamentary democracies, especially Austria and Italy.

The space of bargaining outcomes is denoted as $\bar{X}=X \cup\left\{q^{o}\right\}$, where $x \neq q^{o}$ denotes a successful bargain implementing the policy $x$, and $x=q^{o}$ denotes bargaining failure resulting in the status quo policy $q$. Note that $x=q$ denotes the coalition agreeing to pass the policy $q$, and $q^{o}$ denotes the status quo prevailing as a result of bargaining failure. We extend the utility functions over $\bar{X}$ by letting $u_{i}\left(q^{o}\right)=u_{i}(q)$ and $v_{\ell}\left(q^{o}\right)=v_{\ell}(q)$, so $u_{i}\left(q^{o}\right)$ denotes legislator $i$ 's policy utility from the bargaining outcome of failure, which is simply his utility from the status quo policy.

The lobbying is assumed to track the governing process. The first lobbying stage occurs after the selection of a formateur, and lobbies make offers to the formateur to influence the choice of a coalition for subsequent bargaining. Formally, lobby $\ell$ offers coalition-contingent contribution schedules $H_{\ell}(A ; q), A \in D^{f} \cup \emptyset$, to the formateur $f .{ }^{3}$ The offers are assumed to be credible in the sense that once an offer has been made a lobby fulfills its terms. An offer to influence the choice of a coalition thus cannot be rescinded or negated in the legislative stage of lobbying, even if the selected coalition ultimately fails to reach a bargain. This is equivalent to the offer to influence coalition selection being paid immediately after coalition selection.

\footnotetext{
${ }^{3}$ Lobbies are assumed to be unable to influence the selection of the formateur. In a parliamentary system that selection could be specified by a constitution, determined by a monarch, or based on norms. Similarly, in the legislative bargaining the lobbies are assumed to be unable to influence the selection of the proposer.
} 
The second lobbying stage occurs in the subgame commencing after the selection of a coalition but prior to the commencement of bargaining. Lobbies make credible offers to legislators to influence the platform selected, and they may condition their offers on any observable in the bargaining outcome. These observables are assumed to be whether the bargaining succeeds or fails and in the event of success the agreed upon policy.

Let lobby $\ell$ 's contribution schedule for the subgame with history $(A, q)$ be $C_{\ell j}(x ; A, q) \geq 0$, which is paid to legislator $j$ if and only if the bargaining outcome is $x \in \bar{X}$. A positive offer $C_{\ell j}\left(q^{o} ; A, q\right)>0$ to a legislator $j \in A$ in support of bargaining failure provides that legislator with an incentive to vote against any platform if he is not recognized to be the proposer, and an incentive to propose a platform that will be rejected by the coalition if he is recognized. ${ }^{4,5}$ A lobby that prefers the status quo thus has two opportunities to preserve it. First, it can induce the formateur to choose $\emptyset$ in the coalition selection stage. Second, it can induce the coalition to reject a proposed platform by contributing $C_{\ell j}\left(q^{o} ; A, q\right)$ in favor of the status quo.

For simplicity we assume that lobbies do not observe the votes of individual legislators, the identity of the proposer, the vector of transfers supporting the policy, or the proposal that was made in the event of bargaining failure. Allowing the lobbies to observe these features of the bargaining has no effect on the set of achievable equilibrium payoff vectors within the class of equilibria we consider. Intuitively, the reason is that these observables are not payoff-relevant to the lobbies. ${ }^{6}$ Substantively, our assumptions correspond to a parliamentary system in which the proto-coalition bargains behind closed doors.

The utility $V_{\ell}(x, A ; q)$ of a lobby $\ell$ is assumed to be quasilinear and is given by

$$
V_{\ell}(x, A ; q)=\left\{\begin{array}{cc}
v_{\ell}(x)-H_{\ell}(A ; q)-\sum_{i \in P} C_{\ell i}(x ; A, q) & \text { if } A \text { agrees to } x \\
v_{\ell}(q)-H_{\ell}(A ; q)-\sum_{i \in P} C_{\ell i}\left(q^{o} ; A, q\right) & \text { if } A \text { fails to agree } \\
v_{\ell}(q)-H_{\ell}(\emptyset ; q) & \text { if } A=\emptyset .
\end{array}\right.
$$

\footnotetext{
${ }^{4}$ A lobby never offers a contribution to a legislator not in $A$, since that legislator is not pivotal.

${ }^{5}$ With a sequential bargaining protocol contributions $C_{\ell j}\left(q^{o} ; A, q\right)$ are also paid if the coalition collapses exogenously. A coalition member $j$ thus can reject a proposal, resulting in defeat with probability $r$. Alternatively, at the investiture or voting stage he can vote against the coalition and its policy resulting in failure with probability one.

${ }^{6}$ To argue this informally for conditioning on individual votes, suppose that all lobbies but one use contribution schedules that do not depend on a legislator vote. The remaining lobby could offer to a pivotal voter a lump sum for a no vote, but this is allowed in the class of contribution schedules used in the model. If a lobby offered a lump sum for a yes vote, the lobby could equivalently increase its contribution schedule for approval of the proposal by that amount. Hence, the lobby has as a best response a contribution schedule that does not depend on the vote of an individual legislator. This implies that the model applies to a legislature where votes are observable.
} 
A legislator $i$ has preferences represented by a quasilinear utility function $U_{i}$ specified as ${ }^{7}$

$$
U_{i}=\left\{\begin{array}{cc}
\alpha_{i} u_{i}(x)+s_{i}+I \cdot \sum_{\ell \in L} H_{\ell}(A ; q)+\sum_{\ell \in L} C_{\ell i}(x ; A, q) & \text { if } A \text { agrees to } x \\
\alpha_{i} u_{i}(q)+s_{i}+I \cdot \sum_{\ell \in L} H_{\ell}(A ; q)+\sum_{\ell \in L} C_{\ell i}\left(q^{o} ; A, q\right) & \text { if } A \text { fails to agree } \\
\alpha_{i} u_{i}(q)+I \cdot \sum_{\ell \in L} H_{\ell}(\emptyset ; q) & \text { if } A=\emptyset,
\end{array}\right.
$$

where $I=1$ if $i=f$ and 0 otherwise.

\subsection{Proto-Coalition Bargaining}

The model can be thought of as a "proto-coalition" bargaining game, in which a formateur first selects a coalition, and once a coalition has been selected its members bargain over the policy and officeholding benefits. Axelrod (1970) introduced the concept of a proto-coalition, and proto-coalition bargaining has been used by Diermeier (2006), Diermeier, Eraslan, and Merlo (2002)(2003), and Baron and Diermeier. Felli and Merlo (2006) use a similar protocol in a citizen-candidate model where the elected candidate chooses a subset of lobbies with which to bargain. As in our model these authors require unanimity among all the members of the proto-coalition before the coalition can take office and implement a policy. ${ }^{8}$

In the model the import of proto-coalition bargaining is to make each legislator in $A$ pivotal, which allows surplus coalitions to be formed in equilibrium. If only a majority is required for approval, all equilibrium coalitions are minimal winning. The bargaining power of a proposer depends in part on this assumption. The larger the proto-coalition the greater is the surplus over which the members bargain but the smaller is the bargaining power of any member of the proto-coalition. The equilibria are characterized for status quos covering the entire policy space, so bargaining power, the policy, and coalition membership vary with the status quo.

In the model the formateur is assumed to select a proto-coalition based on her induced preferences. Proto-coalition formation could involve a process through which members are included by the formateur. Grofman (1982) assumed a hierarchical process, whereas Laver (1992) considers an alternative process. Laver and Schofield (1991, p. 138) describe Laver's process as: "In addition to a hierarchical process of coalition building in which proto-coalitions which form along the way go on to behave as if they were single actors, he suggests a hierarchical process in which the parties bind themselves together, but none the less continue to evaluate as individuals the alternatives on offer." In our model the proto-coalition members "bind themselves together" in the coalition formation stage, yet act independently in the subsequent legislative bargaining.

A number of institutional arrangements could correspond to a model of proto-coalition bargaining. In a legislative context it could be a consequence of the proposer's ability to credibly commit to withdraw a

\footnotetext{
${ }^{7}$ Including a weight on the officeholding benefits has no effect on the equilibria.

${ }^{8}$ Siedmann, Winter, and Pavlov (2007) also require unanimity.
} 
proposal if there were a defection. One way the proposer could make her commitment credible is by publicly announcing the bargain and praising the consensus within the coalition. If the consensus were violated by a defection, the proposer would suffer reputation damage and is assumed to prefer to call off the bargain.

Proto-coalition bargaining could also be a consequence of parliamentary government formation. For example, the formateur chooses a proto-coalition of parties with which to bargain over the formation of a government. Once the bargaining among the members of the proto-coalition is concluded, the coalition is presented as the government with the agreed-to policy, and then an investiture vote on the government and its policy occur. If the coalition breaks; i.e., unanimous agreement among its members is not attained, the government formation attempt fails, no officeholding benefits are received, and the status quo remains in

effect. An election then could be called. A proto-coalition could be selected after an election or it could be selected prior to an election and hence have (unmodeled) electoral effects as well as the governing effects modeled here. Empirical studies of proto-coalitions include Golder (2005, 2006), Martin and Stevenson (2001), and Strom and Muller (1999). Debus (2009) identified 73 pre-election coalitions in 5 European countries, and 23 were able to form a government given the election outcome.

This model could also be interpreted as corresponding to a parliamentary system with a government of cabinet form, where a cabinet is formed among the supporting coalition and must agree to a policy with unanimity for it to be considered for enactment by the parliament. The coalition selection stage then corresponds to the selection of a government (where no investiture vote is required) and the identification of the cabinet. The legislative bargaining stage then corresponds to governing; i.e., choosing a policy and an allocation of officeholding benefits. Under a cabinet form of governing the policy and transfers must be agreed to by all members of the cabinet before they take effect.

\section{$2.3 \quad$ Timing}

The model pertains to a single period that can be thought of as an interelection period. The model has two stages - a coalition selection stage and a legislative bargaining stage - and lobbying has two components that correspond to these stages. More formally, the stages of the full game are:

\section{- COALITION SELECTION STAGE ${ }^{9}$}

1. A legislator $f$ is selected to be the formateur.

2. Each lobby offers the formateur a contribution schedule $H_{\ell}(A ; q)$ to support the choice of a coalition $A \in\left\{D^{f} \cup \emptyset\right\}$.

\footnotetext{
${ }^{9}$ The lobbies could make their offers before the formateur was selected, and the coalition selection and equilibrium legislative bargaining would be unaffected. The lobbies would offer contributions condition on the identity of the formateur.
} 
3. The formateur announces a coalition $A$ with which she intends to bargain, and the contribution schedules $H_{\ell}(A ; q)$ are paid. If the formateur chooses $\emptyset$, the coalition formation attempt fails, the status quo prevails, $H_{\ell}(\emptyset ; q)$ is paid, and the game ends. If $A \neq \emptyset$ is chosen, the coalition members bargain.

- LEGISLATIVE BARGAINING AND VOTING STAGE

1. Given a history $(A, q)$, each lobby $\ell$ announces contribution schedules $C_{\ell j}(x ; A, q), \forall x \in \bar{X}$, for legislator $j \in P$, which are paid if and only if the bargaining outcome is $x \in \bar{X}$.

2. After observing the announced schedules, a proposer $p \in A$ is selected at random to make a take-it-or-leave-it proposal of a platform consisting of a policy $x$ and a vector $s .{ }^{10}$

3. Legislators in the coalition simultaneously accept or reject the proposal. The proposal fails if $z_{j}=0$ for any $j \in A$ in which case the status quo prevails and the proposed allocation of officeholding benefits is called off.

4. If the proposal is accepted, all offers $C_{\ell j}(x ; A, q)$ are paid and the platform $(x, s)$ is implemented.

The solution concept is subgame perfect equilibrium.

\section{Equilibrium Characterization}

\subsection{Policy Lobbying and Legislative Bargaining}

We begin by characterizing equilibrium legislative bargaining outcomes given a profile of contribution schedules $C_{\ell j}(x, A ; q)$. The legislative bargaining game begins with the random recognition of a proposer $p \in A$ to make a take-it-or-leave-it offer of platform $(x, s) \in X \times S$. We assume that $\operatorname{Pr}(j=p)=\frac{1}{|A|}$ for all $j \in A$, i.e., the coalition legislators are recognized with equal probability. Since the formateur is not advantaged at the bargaining stage, increasing the size of the coalition dilutes the formateur's anticipated bargaining power by diminishing his recognition probability.

Absent transfers, a legislator $j$ receives utility $\alpha_{j} u_{j}(x)+\sum_{\ell \in L} C_{\ell j}(x ; A, q)$ from a bargaining outcome $x$, which is his policy utility plus any lobbying contributions offered for that outcome. Since any legislator can unilaterally induce bargaining failure by rejecting the proposal, his reservation value is $\alpha_{j} u_{j}\left(q^{o}\right)+$ $\sum_{\ell \in L} C_{\ell j}\left(q^{o} ; A, q\right)$, which is his utility from the status quo policy plus any lobbying contributions he receives in the event of bargaining failure.

\footnotetext{
${ }^{10}$ Felli and Merlo use take-it-or-leave-it bargaining.
} 
The aggregate bargaining surplus $R(x ; A, q)$ of coalition $A$ generated by implementing an outcome $x \in \bar{X}$ thus is

$$
R(x ; A, q)=\sum_{j \in A}\left(\alpha_{j} u_{j}(x)+\sum_{\ell \in L} C_{\ell j}(x ; A, q)\right)+\bar{S}-\sum_{j \in A}\left(\alpha_{j} u_{j}\left(q^{o}\right)+\sum_{\ell \in L} C_{\ell j}\left(q^{o} ; A, q\right)\right),
$$

where $\bar{S}$ is the aggregate officeholding benefits available for a coalition that successfully governs. If the coalitions fails to adopt a proposal, $R\left(q^{o} ; A, q\right)=0$. Note that a legislator's reservation value depends on the status quo $q$, since $\alpha_{j} u_{j}\left(q^{o}\right)=\alpha_{j} u_{j}(q)$. Thus, at the initial coalition formation stage legislators who are disadvantaged by the status quo are more attractive coalition partners all else equal, since their contribution to the aggregate bargaining surplus will be larger.

The surplus $R(x ; A, q)$ may be negative for all $x \in X$ if lobbies make sufficiently large contributions in favor of the status quo, in which case the coalition is better off allowing the bargain to fail, resulting in $R\left(q^{o} ; A, q\right)=0$. In the class of equilibria we consider, the aggregate bargaining surplus is always weakly positive for some $x \in X$, and permitting the bargaining to fail is never an equilibrium strategy for the proposer.

Once a proposer is recognized, he can extract the coalition's full aggregate surplus from a policy $x \in X$ by setting the optimal transfers $s_{j}^{*}(x)$ to leave each coalition partner $j \in A \backslash p$ indifferent between bargaining success and failure. A coalition member will accept $\left(z_{j}=1\right)$ any platform that leaves him at least as well off as bargaining failure. ${ }^{11}$ Coalition members who initially prefer bargaining failure receive positive transfers, while those who initially prefer policy $x$ receive negative transfers, and the proposer is the residual claimant. Conditioning proposals on acceptance by all legislators in a decisive coalition thus allows the proposer to exchange officeholding benefits for policy concessions with those legislators.

Should the bargaining surplus be negative for every policy, the proposer can implement bargaining failure by choosing any policy $x$ and setting transfers such that at least one legislator is better off with failure, or

$$
s_{j}<\left(\alpha_{j} u_{j}\left(q^{o}\right)+\sum_{\ell \in L} C_{\ell j}\left(q^{o} ; A, q\right)\right)-\left(\alpha_{j} u_{j}(x)+\sum_{\ell \in L} C_{\ell j}(x ; A, q)\right) \text { for some } j \in A .
$$

That legislator then rejects the proposal, the status quo prevails, all transfers are called off, and no surplus results. The proposer's utility from the optimal implementation of any bargaining outcome $x \in \bar{X}$ is therefore

$$
R(x ; A, q)+\alpha_{p} u_{p}\left(q^{o}\right)+\sum_{\ell \in L} C_{\ell p}\left(q^{o} ; A, q\right),
$$

or the full bargaining surplus plus his own reservation value. ${ }^{12}$

\footnotetext{
${ }^{11}$ The member does not have an incentive to free-ride on the affirmative vote of other members by rejecting negative transfers, since each member is pivotal.

${ }^{12}$ In expectation any coalition member receives only $\frac{1}{|A|} R(x ; A, q)$.
} 
Having characterized the optimal transfers, the first result regarding bargaining outcomes can be stated. For simplicity, denote lobby $\ell$ 's aggregate contribution to the coalition $A$ in favor of the bargaining outcome $x \in \bar{X}$ as $C_{\ell}(x ; A, q)=\sum_{j \in A} C_{\ell j}(x ; A, q)$.

Lemma 1 In a legislative bargaining equilibrium, every legislator $j \in A$ when recognized implements an outcome $x_{j}^{*}$ satisfying

$$
x_{j}^{*} \in X^{*}(A, q) \equiv \arg \max _{x \in \bar{X}}\left\{\sum_{j \in A} \alpha_{j} u_{j}(x)+\sum_{\ell \in L} C_{\ell}(x ; A, q)\right\} .
$$

Proof: It is straightforward to see that a bargaining outcome maximizes the proposer's utility if and only if it maximizes the aggregate bargaining surplus $R(x ; A, q)$ (noting that $R\left(q^{o} ; A, q\right)=0$ ). The statement then follows immediately from (3) and (4).

By compactness of the policy space the set of maximizers $X^{*}(A, q)$ of $R(x ; A, q)$ will be nonempty when the aggregate contribution functions are continuous. In the class of lobbying equilibria we consider in Section 4 the aggregate contribution schedules will be such that there is a unique interior optimum.

The lemma states that every legislator, when recognized as the proposer, chooses policy as if he were unitary decision maker with a utility function corresponding to the aggregate policy preferences $\sum_{j \in A} \alpha_{j} u_{j}(x)$ of the coalition members and who receives the aggregate outcome-contingent contributions $\sum_{\ell \in L} C_{\ell}(x ; A, q)$ of the lobbies. Consequently, every proposer will choose from the same set $X^{*}(A, q)$ in (5) that maximizes aggregate policy utility and contributions. The result is a direct consequence of efficient proto-coalition bargaining and does not depend on the specific assumption of take-it-or-leave-it offers. With the sequential bargaining protocol the same result obtains.

The key implications of Lemma 1 for policy lobbying are two-fold. First, the lobbies do not need to know the identity of the proposer to determine the effect of their contributions on policy choice, since all legislators face the same optimization problem over the set of bargaining outcomes when they are the proposer. Second, the allocation of contribution offers among the coalition members $\sum_{\ell \in L} C_{\ell j}(x ; A, q)$ is both payoff and strategically irrelevant to the lobbies, since only total contributions influence policy choice.

To characterize the set of equilibria to the policy lobbying stage, note that Lemma 1 implies that the policy lobbying stage is strategically equivalent to a standard common agency lobbying game in which a unitary decision maker has the aggregate preferences of the proto-coalition and receives the aggregate contributions for each bargaining outcome. Lemma 2 of Bernheim and Whinston (1986a) thus can be used to characterize the set of pure strategy equilibria. 
Lemma 2 There exists a pure strategy equilibrium of the subgame commencing with policy lobbying, in which contribution schedules are $C_{\ell j}^{*}(x ; A, q), \ell \in L$, and every proposer implements outcome $x^{*}$ if and only if

(i) $C_{\ell j}^{*}(x ; A, q) \geq 0, \forall \ell \in L, j \in P, x \in \bar{X}$ and $C_{\ell j}^{*}(x ; A, q)=0, \forall j \notin A$.

(ii) $x^{*} \in X^{*}(A, q) \equiv \arg \max _{x \in \bar{X}}\left\{\sum_{j \in A} \alpha_{j} u_{j}(x)+\sum_{\ell \in L} C_{\ell}^{*}(x ; A, q)\right\}$.

(iii) For every $k \in L, x^{*} \in \arg \max _{x \in \bar{X}}\left\{v_{k}(x)+\sum_{j \in A} \alpha_{j} u_{j}(x)+\sum_{\ell \in L \backslash k} C_{\ell}^{*}(x ; A, q)\right\}$.

(iv) For every $k \in L$ there exists $\hat{x}^{k}$ satisfying property (ii) with $C_{k}^{*}\left(\hat{x}^{k} ; A, q\right)=0$.

Proof: The proof is straightforward from Lemma 1 and Lemma 2 of Bernheim and Whinston (1986a).

The properties of a pure strategy equilibrium to the policy lobbying stage are standard from common agency. Property (i) is feasibility of the contribution schedules and furthermore states that the lobbies make no contributions to legislators outside the proto-coalition since they have no policy influence. Property (ii) states that the induced outcome $x^{*}$ is an optimal proposal in the legislative bargaining game. Properties (iii) and (iv) together ensure optimality of the lobbyists' contribution schedules. The former ensures that no lobby finds it profitable to induce an alternative outcome in the bargaining, given the contribution schedules of the other lobbies. The latter ensures that no lobby can reduce its contribution for the equilibrium outcome without inducing a different bargaining outcome.

The equilibrium policy in the subgame commencing after the choice of $A$ reflects the interests of both the legislators in $A$ and the lobbies. The lobbies thus directly influence policy, and the extent of their influence depends on the preference parameters $\alpha_{j}$ and the policy utility functions $u_{j}(x)$ and $v_{\ell}(x)$. The greater is $\alpha_{j}, j \in A$, the less influence every lobby has, since contributions are less important to the legislator. The more extreme are the preferences of a lobby the greater is its influence. This means that the equilibrium policy can, for example, be outside the Pareto set of the legislators' preferences.

The lobbies are indifferent to how they allocate their aggregate contributions among the individual coalition members, but the expected payoffs of the legislators are determined by the specific allocations. In a lobbying equilibrium of the subgame commencing with the selection of $A$ and in which $x^{*}$ is the bargaining outcome, the players' ex-ante expected utilities are:

1. Lobbies receive $v_{\ell}\left(x^{*}\right)-C_{\ell}^{*}\left(x^{*} ; A, q\right)$.

2. Legislators receive

$$
E U^{i}\left(x^{*}, A, q\right)=\frac{1}{|A|} R\left(x^{*} ; A, q\right)+\alpha_{i} u_{i}\left(q^{o}\right)+\sum_{\ell \in L} C_{\ell i}^{*}\left(q^{o} ; A, q\right) .
$$


In expectation, each legislator in the coalition receives an equal share of the bargaining surplus $R\left(x^{*} ; A, q\right)$ because each has an equal probability of being the proposer and the size of the bargaining surplus is unaffected by how the lobbies allocate their offers. However, each legislator also receives his own reservation value $\alpha_{i} u_{i}\left(q^{o}\right)+\sum_{\ell \in L} C_{\ell i}\left(q^{o} ; A, q\right)$, which is in part determined by his share of the contributions that lobbies make to elicit bargaining failure. ${ }^{13} \mathrm{~A}$ shift of offers $C_{\ell}\left(q^{o} ; A, q\right)$ for bargaining failure from legislator $j$ to legislator $i$ increases $i$ 's reservation value and thus his bargaining power. How the lobbyists allocate their contributions on each path of play thus can influence the formateur's expected utility from choosing each possible proto-coalition $A \in D^{f}$ and hence affects the choice of coalition in the first stage of the game.

\subsection{Coalition Selection}

The coalition selection game commences with the formateur's choice of a coalition based on his expected equilibrium payoffs in each subgame. Prior to coalition selection the lobbies make offers $H_{\ell}(A ; q)$ in favor of each potential coalition $A \in D^{f} \cup \emptyset$. The lobbies' offers may be interpreted as the "bidding up" of contributions, beyond what is necessary to have policy influence after the coalition is selected, to induce a coalition for which the policy lobbying, legislative bargaining equilibrium is favorable. The "bidding up" coalition selection game is a common agency lobbying game with a finite action space and is defined as follows.

\section{Coalition Selection Common Agency Lobbying Game}

Begin by selecting equilibrium contribution schedules $C_{\ell j}^{*}(x, A ; q)$ and legislative bargaining outcome $x^{*} \in X^{*}(A, q)$ jointly satisfying Lemma 2 for each of the continuation games corresponding to $A \in D^{f}$.

1. Lobbies offer contribution schedules $H_{\ell}(A ; q)$ to the formateur that are paid if and only if coalition $A \in D^{f} \cup \emptyset$ is selected.

2. The formateur chooses from the set $D^{f} \cup \emptyset$.

3. The formateur's continuation utility from no coalition $\emptyset$ is $\alpha_{f} u_{f}(q)$. The formateur's continuation expected utility from each choice $A \in D^{f}$ is $E U^{f}\left(x^{*}, A, q\right)$ from (6).

4. Lobby $\ell$ 's continuation utility from $\emptyset$ is $v_{\ell}(q)$, and from $A \in D^{f}$ is

$$
v_{\ell}\left(x^{*}\right)-C_{\ell}^{*}\left(x^{*} ; A, q\right) .
$$

\footnotetext{
${ }^{13}$ With the sequential bargaining protocol the equilibrium platform $\left(x^{*}, s\right)$ includes an equal share $\left(s_{i}=\frac{1}{|A|} R\left(x^{*} ; A, q\right)\right)$ of the surplus plus the reservation value of the coalition member. In a government formation context the shares could include the allocation of ministries and other officeholding benefits, as represented by $\bar{S}$. With random recognition each coalition member has an expected share $\frac{1}{|A|} \bar{S}$.
} 
The formateur's expected payoff $E U^{f}\left(x^{*}, A, q\right)$ from choosing a coalition $A \in D^{f}$ has three components. The first is the coalition's aggregate bargaining surplus $R\left(x^{*} ; A, q\right)$. The second is the size of the coalition $|A|$, which determines the formateur's share of the surplus. Since all coalition legislators have an equal probability of being recognized to make a proposal, the coalition size reflects the formateur's expected bargaining power. The formateur has an incentive to choose a larger coalition, since that would increase the total surplus, but she also has a disincentive to do so because her expected bargaining power is reduced. The third is the formateur's reservation value, comprised of her utility from the status quo $\alpha_{f} u_{f}(q)$ and her total share of lobbying contributions in favor of bargaining failure $\sum_{\ell \in L} C_{\ell f}\left(q^{o} ; A, q\right)$. The formateur's expected utility from (6) may be rewritten as

$$
\begin{aligned}
& E U^{f}\left(x^{*}(A), A, q\right)=\frac{1}{|A|}\left(\sum_{j \in A} \alpha_{j} u_{j}\left(x^{*}\right)+\sum_{\ell \in L} C_{\ell}^{*}\left(x^{*} ; A, q\right)+\bar{S}-\sum_{j \in A} \alpha_{j} u_{j}\left(q^{o}\right)\right) \\
& +\alpha_{f} u_{f}(q)+\left(\delta_{f}^{* A}-\frac{1}{|A|}\right) \sum_{\ell \in L} C_{\ell}^{*}\left(q^{o} ; A, q\right),
\end{aligned}
$$

where $\delta_{i}^{* A}=\frac{\sum_{\ell \in L} C_{\ell i}^{*}\left(q^{o} ; A, q\right)}{\sum_{\ell \in L} C_{\ell}^{*}\left(q^{o} ; A, q\right)}$ represents legislator $i$ 's proportion of total contributions $C_{\ell}^{*}\left(q^{o} ; A, q\right)$ in favor of bargaining failure. The greater the formateur's share $\delta_{f}^{* A}$, holding the $C_{\ell}^{*}\left(q^{o} ; A, q\right)$ fixed, the greater is her bargaining power in that subgame, but by Lemma 2 it does not affect the equilibrium policy. Thus, every equilibrium profile of aggregate schedules $C_{\ell}^{*}\left(q^{o} ; A, q\right)$ and outcome $x^{*}$ gives rise to a continuum of possible equilibrium payoffs for the formateur, and the equilibrium selection on each path of play affects the formateur's choice of coalition.

Although a greater $\delta_{f}^{* A}$ does not affect the choice of a policy, it does affect the formateur's preferences over coalitions. The greater are the contributions to the formateur in opposition to the coalition A and its policy $x^{*} \in X^{*}(A, q)$, the greater is her bargaining power in the subgame commencing with the selection of $A{ }^{14}$ The greater bargaining power thus strengthens the formateur's preferences for the coalition. Greater contributions to the formateur in opposition to $A$ thus have the anomalous effect of making $A$ more attractive to the formateur. This observation also applies to a fixed $\delta_{f}^{* A}$ and greater contributions $C_{\ell}^{*}\left(q^{o} ; A, q\right)$ in opposition to $A$.

Necessary and sufficient conditions for an equilibrium to the coalition choice lobbying game are those in Bernheim and Whinston Lemma 2 rewritten with the appropriate payoffs from the game described above, and these are presented in Appendix A. Combining this observation with the previous analysis provides necessary and sufficient conditions for a subgame perfect equilibrium of the full model.

\footnotetext{
${ }^{14}$ Recall that lobbies cannot commit in the coalition selection stage to their contributions in the legislative bargaining stage.
} 
Lemma 3 There exists a pure strategy equilibrium of the coalition selection lobbying stage with contribution schedules $H_{\ell}^{*}(A ; q), \ell \in L$, and the coalition selection $A^{*} \in D^{f} \cup \emptyset$ if and only if

1. There exists $C_{\ell j}^{*}(x, A ; q), j \in A$, and $x^{*} \in X^{*}(A, q)$ for every $A \in D^{f}$ such that $H_{\ell}^{*}(A ; q), \ell \in L$, and $A^{*} \in D^{f} \cup \emptyset$ form a pure strategy equilibrium of the induced coalition selection common agency lobbying game.

2. $C_{\ell j}^{*}(x, A ; q), j \in A, \ell \in L$, and $x^{*} \in X^{*}(A, q)$ satisfy Lemma 2 for every $A \in D^{f}$.

Proof: Backward induction.

This completes the general characterization of equilibria in the full common agency majority rule game. There is a continuum of equilibria to this game, and they are not payoff equivalent, nor do they all result in the same coalition choice and policy. The next section uses the truthfulness concept from Bernheim and Whinston to refine the set of equilibria. The refined set also contains a continuum of equilibria, but it is strictly smaller. The refinement allows further characterization of the lobbying contributions and is used in the example presented in Section 5 to illustrate the equilibria and the influence of lobbies.

\section{Equilibrium Refinement}

\subsection{Legislative Bargaining Stage}

Truthfulness is applied here both to the legislative bargaining stage in which lobbying occurs over platforms and to the coalition formation stage in which lobbying occurs over coalition selection. Truthfulness allows an explicit characterization of lobbying contributions and a deeper intuition into the equilibrium coalition and policy. A lobby $\ell$ 's set of contribution schedules $C_{\ell j}(x ; A, q)$ for each $j \in A$ are truthful relative to a bargaining outcome if that lobby's aggregate contributions reflect its marginal willingness to pay and thus reflect its true preferences for those bargaining outcomes and coalitions for which the lobby offers a positive contribution. Hence,

Definition 1 A lobby's contribution schedules $C_{\ell j}^{T}(x ; A, q)$ over policies $x \in \bar{X}$ are truthful if there exists a constant $B_{\ell}^{A}$ such that for $x \in X$

$$
C_{\ell}^{T}(x ; A, q)=\sum_{j \in A} C_{\ell j}^{T}(x ; A, q)=\max \left\{v_{\ell}(x)-B_{\ell}^{A}, 0\right\},
$$

and

$$
v_{\ell}\left(x^{A}\right) \geq B_{\ell}^{A},
$$

where $x^{A}$ is the equilibrium outcome of the legislative bargaining with truthful contribution schedules. 
The superscript ${ }^{T}$ will be omitted and the contribution schedules understood to be truthful. Note that truthfulness is not a property of an individual contribution schedule $C_{\ell j}(x, A ; q)$ offered to a legislator $j \in A$ but rather a property of the aggregate contribution schedules $C_{\ell}(x ; A, q)$. In the subgame equilibrium in which the coalition is $A, B_{\ell}^{A}$ is lobby $i$ 's payoff.

Truthfulness requires a positive contribution for bargaining failure $C_{\ell}\left(q^{o} ; A, q\right)>0$ whenever lobby $\ell$ strictly prefers the status quo $q$ to the equilibrium payoff $B_{\ell}^{A}$. In addition, truthfulness implies that $C_{\ell}(q ; A, q)=\max \left\{v_{\ell}(q)-B_{\ell}^{A}, 0\right\}=\max \left\{v_{\ell}\left(q^{o}\right)-B_{\ell}^{A}, 0\right\}=C_{\ell}\left(q^{o} ; A, q\right)$. In other words, a lobby must offer the same aggregate contributions regardless of whether the status quo prevails by being passed $\left(x^{A}=q\right)$ by the coalition or by bargaining failure, since the lobbies value either outcome identically. Although the truthfulness refinement imposes no restriction on the legislators' individual shares of the aggregate contribution schedules, those shares are payoff relevant to the legislators in the bargaining.

Bernheim-Whinston Theorem 2 shows that the set of truthful equilibria in a common agency game may be fully characterized as the Pareto frontier of a restricted equilibrium payoff set for the lobbies. The restrictions are characterized by what the coalition members and other lobbies may jointly achieve when the interests of a particular lobby (or set of lobbies) are ignored. The following notation is useful in that characterization.

1. Define $Z_{-J}(x, A)$ as the aggregate policy utility of coalition $A$ and the lobbies not in the set $J \in 2^{L}$ when the bargaining outcome $x \in \bar{X}$ prevails; i.e.,

$$
Z_{-J}(x, A)=\sum_{j \in A} \alpha_{j} u_{j}(x)+\sum_{\ell \in L \backslash J} v_{\ell}(x) .
$$

2. Let $x_{-J}^{A}=\arg \max _{x \in \bar{X}} Z_{-J}(x, A)$, which is independent of $q$ and generically unique since the policy utility functions are strictly concave. ${ }^{15}$ Let $Z_{-\emptyset}(x, A)=Z(x, A)$ and $x_{-\emptyset}^{A}=x^{A}$, which is the coalitionplus-lobbies efficient policy.

We now characterize the set of truthful equilibria to the policy lobbying stage.

Proposition 1 There exists a pure strategy equilibrium of the policy lobbying subgame with truthful contribution schedules $C_{\ell j}^{*}(x ; A, q), \ell \in L, j \in A$, and in which every proposer implements $x^{*}$ if and only if

1. $x^{*}=x^{A}$.

2. The equilibrium net payoff vector $B^{* A} \in \Re^{\bar{L}}$ of the lobbies satisfies the following $2^{\bar{L}}-1$ inequalities

$$
\forall J \in 2^{L} \backslash \emptyset, \quad \sum_{\ell \in J} B_{\ell}^{* A} \leq Z\left(x^{A}, A\right)-Z_{-J}\left(x_{-J}^{A}, A\right) .
$$

\footnotetext{
${ }^{15}$ Non-uniqueness only fails in the nongeneric case in which $q$ is the unique optimum, in which case both $q$ and $q^{o}$ are maximizers and either may be used.
} 
3. There exists no vector $\hat{B}^{A} \in \Re^{\bar{L}}$ satisfying the conditions in (8) such that $\hat{B}^{A} \geq B^{* A}$ and $\hat{B}_{\ell}^{A}>B_{\ell}^{* A}$ for some $\ell \in L$.

Proof: Lemma 2 and Bernheim and Whinston Theorem 2.

Property 2 of Proposition 1 characterizes the set of feasible equilibrium net payoff vectors $B_{\ell}^{* A}$ for the lobbies; those in which the contributions of every subset of lobbies are at least as large as the externality imposed on the other players by considering their interests. Property 3 states that the set of truthful equilibria correspond to the Pareto frontier of this set; i.e., no lobby or subset of lobbies can successfully lower their (truthful) contribution schedules by some constant without having their interests ignored.

Note that the set of $B_{\ell}^{* A}$ is unaffected by the specific choice of bargaining protocol. Lemma 1 applies whenever proto-coalition bargaining is efficient, since bargaining outcomes must maximize the aggregate bargaining surplus $R(x, A ; q)$. The $B_{\ell}^{* A}$ satisfying (8) need not be unique, and in the example presented in Section 5 there is a continuum of values for the $B_{\ell}^{* A}$ for each $A \in D^{f}$. These need not be payoff equivalent for the formateur and hence can affect the formateur's choice of a coalition in the first stage of the game.

\subsection{Further Characterization of Equilibria}

\subsubsection{Coalition Efficiency}

The bargaining outcome $x^{A}$ in Proposition 1 is coalition efficient in the sense that it maximizes the aggregate utility of the coalition members and the lobbies that contribute to them in the subgame commencing with the selection of $A$. The aggregate payoff to the coalition and the lobbies is

$$
Z\left(x^{A}, A\right)=\sum_{j \in A} \alpha_{j} u_{j}\left(x^{A}\right)+\sum_{\ell \in L} v_{\ell}\left(x^{A}\right)
$$

The bargaining outcome $x^{A}$ thus in effect is chosen as

$$
x^{A}=\arg \max _{x \in \bar{X}}\left\{\sum_{j \in A} \alpha_{j} u_{j}(x)+\sum_{\ell \in L} v_{\ell}(x)\right\} .
$$

The proposer thus acts as if he maximizes the utility of the coalition members and the lobbies that contribute to them.

Because the bargaining failure outcome $q^{o}$ is the coalition-efficient outcome only in the knife-edge case in which the prevailing status quo policy $q$ is coalition-efficient, the truthfulness refinement implies that generically bargaining failure cannot be an equilibrium outcome. In addition, for any $q$ there exists a truthful equilibrium in which the bargaining is successful, $x^{A} \neq q^{o}$, and the bargaining outcome $x^{A}$ equivalently 
represents a successful bargain that implements policy $x^{A}$. We will henceforth refer to $x^{A}$ as the coalitionefficient policy and assume that the bargaining never fails in equilibrium.

\subsubsection{Special Interest Lobbies and Separable Coalition Preferences}

Uniqueness of the $B_{\ell}^{* A}$ results in the special case in which the following two conditions hold:

1. Lobbies are each concerned with a single non-overlapping policy dimension.

2. The coalition's aggregate policy utility $\sum_{j \in A} \alpha_{j} u_{j}(x)$ is additively separable across dimensions.

A sufficient condition for the second condition is that the preferences of the individual legislators in the coalition are additively separable. A special interest lobby $\ell$ cares only about the policy component $x_{\ell}$, so $v_{\ell}(x)=v_{\ell}\left(x_{\ell}\right)$. A coalition $A$ has separable aggregate preferences if $\sum_{A} \alpha_{j} u_{j}(x)$ can be rewritten as $\sum_{m=1}^{M} U_{m}^{A}\left(x_{m}\right)$, where $U_{m}^{A}(\cdot)$ captures the aggregate preferences of the coalition members along dimension $m$. In this case $x_{-J}^{A}$ is a vector of maximizers $x_{m,-J}^{A}$ on each dimension $m$. If $m \in J$, then $x_{m,-J}^{A}$ maximizes only the utility of the coalition legislators along that dimension. Otherwise $x_{m,-J}^{A}$ maximizes the joint utility of the coalition legislators and lobby $m$. With this structure, the right side of (8) for $J=\{j k\}$ is the sum of the right sides of (8) for $J=\{j\}$ and for $J=\{k\}$. Consequently, the constants $B_{\ell}^{* A}$ are given uniquely by

$$
B_{\ell}^{* A}=Z\left(x^{A}, A\right)-Z_{\{-\ell\}}\left(x_{\{-\ell\}}^{A}, A\right)
$$

In the common agency lobbying model of Grossman and Helpman the utilities $B_{\ell}^{* A}$ are not unique but that is inconsequential for their results, since there is no prior coalition selection stage. In our lobbying model with coalition choice the non-uniqueness can be consequential, since the lobbies' equilibrium payoffs can affect the size of the aggregate bargaining surplus $R(x, A ; q)$ and hence the formateur's preferences over coalitions. Coalition separable preferences and special interest lobbies are strong assumptions, and the example in Section 5 identifies the additional equilibria that result when lobbies have general rather than special interests and coalition preferences are not separable.

\subsubsection{Supporting and Opposing Contributions}

In equilibrium a lobby can make positive contributions in favor of the policy $x^{A}$ and simultaneously offer positive contributions in favor of defeating the coalition that supports it and preserving the status quo. Positive contributions $C_{\ell}\left(x^{A} ; A, q\right)$ require that $v_{\ell}\left(x^{A}\right)>B_{\ell}^{A}$, and positive contributions $C_{\ell}\left(q^{o} ; A, q\right)$ require that $v_{\ell}(q)>B_{\ell}^{A}$. Which contribution offer is the larger simply depends on whether the lobby prefers $x^{A}$ or $q$. Therefore: 
Corollary 1 Truthful contribution offers for and against the proposal $x^{A}$ satisfy

$$
C_{\ell}\left(q^{o} ; A, q\right)>(=)(<) C_{\ell}\left(x^{A} ; A, q\right) \Longleftrightarrow v_{\ell}(q)>(=)(<) v_{\ell}\left(x^{A}\right)
$$

The lobbies that prefer the status quo to $x^{A}$ offer more to induce bargaining failure and preserve the status quo than to support $x^{A}$, but generically the bargaining is always successful because with the truthfulness refinement the coalition efficient policy is chosen. The lobby thus pays $C_{\ell}\left(x^{A} ; A, q\right)$ when $x^{A}$ is chosen by the coalition and never pays $C_{\ell}\left(q^{o} ; A, q\right)$.

\subsubsection{Equilibrium Payoffs}

The equilibrium payoffs of the players in a truthful equilibrium of the subgame commencing after the selection of coalition $A$ are:

1. Lobbies receive $B_{\ell}^{* A}$.

2. Using (7) coalition member $i$ receives

$$
\begin{gathered}
E U^{i}\left(x^{A}, A, q\right)=\alpha_{i} u_{i}(q)+\delta_{i}^{* A} \sum_{\ell \in L} \max \left\{v_{\ell}(q)-B_{\ell}^{* A}, 0\right\} \\
+\frac{1}{|A|}\left[\left(\sum_{j \in A} \alpha_{j} u_{j}\left(x^{A}\right)+\sum_{\ell \in L}\left(v_{\ell}\left(x^{A}\right)-B_{\ell}^{* A}\right)+\bar{S}\right)-\left(\sum_{j \in A} \alpha_{j} u_{j}(q)+\sum_{\ell \in L} \max \left\{v_{\ell}(q)-B_{\ell}^{* A}, 0\right\}\right)\right] .
\end{gathered}
$$

3. Non-coalition members $j \notin A$ receive $\alpha_{j} u_{j}\left(x^{A}\right)$.

Note that the payoffs to the lobbies do not depend on $q$, whereas the payoffs to the coalition members depend on $q$. A policy different from $q$ is (generically) chosen, so $q$ is irrelevant from the lobbies' perspective in the subgames.

A legislator's reservation value and hence equilibrium payoff depends on the status quo in two ways. First, his own utility from bargaining failure is $\alpha_{j} u_{j}(q)$. Second, the total truthful contributions in favor of bargaining failure depend on the strength of the lobbies' preferences for the status quo, and each legislator's reservation value is increased by his share $\delta_{i}^{* A} \sum_{\ell \in L} \max \left\{v_{\ell}(q)-B_{\ell}^{* A}, 0\right\}$ of those contributions.

The preferences given in (11) would govern coalition choice if the lobbies had no incentive to influence the choice in the first stage of the game. The next section introduces truthful contribution schedules to influence the choice of a coalition and provides a characterization of the equilibria of the full game with truthful contribution schedules. 


\subsection{Truthful Equilibrium Characterization for the Full Game}

In the first stage the lobbies offer the formateur contributions in support of coalitions, and they also offer contributions to induce the formateur not to propose a coalition, i.e. the choice space is $D^{f} \cup \emptyset$. The set of equilibrium payoffs for the full common agency lobbying game with the truthfulness refinement can be identified by applying the refinement to both the policy lobbying game and the coalition selection ("bidding up") game. The set of truthful equilibria in the coalition selection stage are defined with respect to an arbitrary selection of a particular truthful equilibrium $\left(x^{A}, C_{\ell j}^{*}(x ; A, q), j \in A, \ell \in L, A \in D^{f}\right)$ in each of the continuation games; i.e., the equilibrium net payoff $B_{\ell}^{* A}$ for each lobby and each coalition member's share $\delta_{i}^{* A}$ of the bargaining failure contributions.

Truthful contribution schedules in the bidding up game again reflect each lobby's marginal willingness to pay for each possible choice by the formateur and are defined as:

Definition $2 A$ contribution schedule $H_{\ell}^{T}(A ; q), A \in D^{f} \cup \emptyset$, is truthful if there exists an $F_{\ell}$ such that

$$
\begin{aligned}
& H_{\ell}^{T}(A ; q)=\max \left\{B_{\ell}^{* A}-F_{\ell}, 0\right\} \text { if } A \in D^{f} \\
& H_{\ell}^{T}(A ; q)=\max \left\{v_{\ell}(q)-F_{\ell}, 0\right\} \text { if } A=\emptyset,
\end{aligned}
$$

and $F_{\ell} \leq B_{\ell}^{* A^{*}}$, where $A^{*}$ is the equilibrium coalition choice.

The superscript ${ }^{T}$ will be understood and omitted hereafter. These contributions represent the bidding up of the lobbies' contribution schedules.

The constant $F_{\ell}$ is the utility of lobby $\ell$ in the full game, and for $A^{*} \in D^{f}$ the lobby can do no better than $B_{\ell}^{* A^{*}}$. A lobby that is worse off in the full game than with the status quo policy (i.e., $v_{\ell}(q)>F_{\ell}$ ) offers contributions in an attempt to induce the formateur not to choose a coalition. A lobby that supports the equilibrium coalition $A^{*}$ with additional contributions $H_{\ell}^{*}\left(A^{*}, q\right)>0$ has utility $F_{\ell}^{*}<B_{\ell}^{* A^{*}}$, where the superscript ${ }^{*}$ denotes an equilibrium value. Note also that in equilibrium a lobby $\ell$ offers contributions $H_{\ell}^{*}(A, q)=B_{\ell}^{* A}-F_{\ell}^{*}$ for an $A \in D^{f} \backslash A^{*}$ preferred to $A^{*}$ in the corresponding subgames, but these contributions are never paid. The coalition utilities $F_{\ell}^{*}$ in a full equilibrium are characterized in Proposition 2 below.

The following notation is used in characterizing the equilibria and is conditioned on a selection of a truthful equilibrium $\left(x^{A}, C_{\ell j}^{*}(x ; A, q)=\max \left\{v_{\ell}(x)-B_{\ell}^{* A}, 0\right\}, \ell \in L, j \in A \in D^{f}\right)$ in each of the subgames.

1. Let $W_{-J}^{f}(A, q)$ be the aggregate utility of the formateur $f$ and the lobbies not in $J \in 2^{L}$ in the 
equilibrium of the subgame in which coalition $A$ was selected. So for $A \in D^{f 16}$

$$
W_{-J}^{f}(A, q)=E U^{f}\left(x^{A}, A, q\right)+\sum_{\ell \in L \backslash J} B_{\ell}^{* A} .
$$

2. Let $W_{-J}^{f}(\emptyset, q)$ be the aggregate utility of the formateur $f$ and the lobbies not in $J$ in the subgame in which no coalition is selected and the status quo prevails, so

$$
W_{-J}^{f}(\emptyset, q)=\alpha_{f} u_{f}(q)+\sum_{\ell \in L \backslash J} v_{\ell}(q)
$$

3. Define the set $A_{-J}^{*}$ as

$$
A_{-J}^{*} \equiv \arg \max _{A \in D^{f} \cup \emptyset}\left\{W_{-J}^{f}(A, q)\right\},
$$

which is the set of optimal coalition choices when the preferences of the lobbies in $J$ are ignored. In an abuse of notation an arbitrary element of the set $A_{-J}^{*}$ is denoted by $A_{-J}^{*}$.

4. As before, for notational simplicity write $W_{-\emptyset}^{f}(A, q)$ as $W^{f}(A, q)$ and $A_{-\emptyset}^{*}=A^{*}$.

The set of truthful equilibria of the first stage coalition bidding up game for an arbitrary selection of truthful equilibria in each continuation game can now be characterized.

Proposition 2 There exists a truthful pure strategy equilibrium of the full game with contribution schedules $H_{\ell}^{*}(A ; q), \ell \in L$, and coalition $A^{*} \in D^{f} \cup \emptyset$, if and only if

1. There exists truthful equilibria $C_{\ell j}^{*}(x, A ; q), j \in A, \ell \in L$, and $x^{A}$ for every $A \in D^{f}$ such that $H_{\ell}^{*}(A ; q), \ell \in L$, and $A^{*} \in D^{f} \cup \emptyset$ form a pure strategy equilibrium of the coalition selection common agency lobbying game.

2.

$$
A^{*} \in \arg \max _{A \in D^{f} \cup \emptyset} W^{f}(A, q) .
$$

3. The lobbies' equilibrium net payoff vector $F^{*} \in \Re^{\bar{L}}$ satisfies the following $2^{\bar{L}}-1$ inequalities

$$
\forall J \in 2^{L} \backslash \emptyset, \quad \sum_{\ell \in J} F_{\ell}^{*} \leq W^{f}\left(A^{*}, q\right)-W_{-J}^{f}\left(A_{-J}^{*}, q\right),
$$

where $W^{f}\left(A^{*}, q\right)-W_{-J}^{f}\left(A_{-J}^{*}, q\right)$ equals

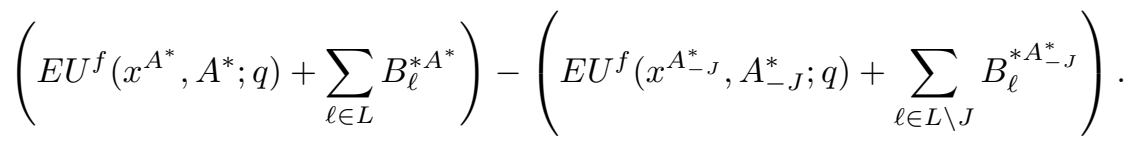

\footnotetext{
${ }^{16}$ Note that this ignores the interests of the lobbies in $J$ in coalition selection but not in the legislative bargaining for the coalition selected.
} 
4. There exists no $\hat{F} \in \Re^{\bar{L}}$ satisfying the conditions in 3 (holding the continuation equilibria fixed) such that $\hat{F} \geq F^{*}$ and $\hat{F}_{\ell}>F_{\ell}^{*}$ for some $\ell \in L$.

Proof: Bernheim and Whinston Theorem 2 and subgame perfection.

Note that $A^{*}$ and the constants $F_{\ell}^{*}$ depend on the status quo and the identity of the formateur, whereas the policy $x^{A}$ and the constants $B_{\ell}^{* A}$ are independent of both.

The equilibrium coalition $A^{*}$ in Proposition 2 maximizes the sum of the formateur's continuation value $E U^{f}\left(x^{A}, A, q\right)$ plus the utility of the lobbies over the subgames. The bidding up contributions $H_{\ell}\left(A^{*} ; q\right)$ then support $A^{*}$ against contributions $H_{\ell}(A ; q), A \in D^{f} \backslash\left\{A^{*} \cup \emptyset\right\}$, offered to elicit the selection of a different coalition. The utility of the formateur is thus the aggregate utility $W^{f}(A, q)$ less the utilities $F_{\ell}^{*}$ of the lobbies.

The formateur's coalition choice maximizes $W^{f}(A, q)$ in $(12)$ and takes into account her utility plus the utilities of the lobbies in the subgames. From (11) the utility of the formateur can be lower in a larger coalition, since the legislative bargaining power is distributed among more legislators. If this dilution effect is greater than the formateur's share of the additional surplus from adding another legislator to the coalition, the formateur can prefer the smaller coalition. Coalition size also affects the influence of lobbies relative to those of the legislators in the coalition selection stage.

Note that in choosing a coalition the formateur takes into account only a $\frac{1}{|A|}$ share of the surplus from the coaltion. In contrast, the interests of all the lobbies are fully taken into account. The interests of the lobbies thus receive $|A|$ times more weight than the interests of the coalition. In contrast, the interests of the lobbies and the coalition receive equal weight in the subgame. In this sense, the lobbies have greater influence in the coalition selection stage than in the legislative bargaining stage.

The equilibrium payoff vector $F^{*}$ for the lobbies is defined relative to the equilibrium coalition choice $A^{*}$, and the truthful contribution schedules $H_{\ell}^{*}(A, q)$ are determined by the difference between $F_{\ell}^{*}$ and the payoff in the subgame commencing with the selection of coalition $A$. Note that the offers $H_{\ell}^{*}(A ; q)$ support the equilibrium coalition and are not directly considered in either the identification of the equilibrium coalition or of the utilities $F_{\ell}^{*}$ of the lobbies. Instead, the offers $H_{\ell}^{*}(A ; q)$ are calculated from their definition given the $F_{\ell}^{*}$. The vector $F^{*}$ need not be unique.

The equilibrium payoffs in a truthful equilibrium of the full game are

1. Lobbies receive $F_{\ell}^{*}$.

2. If $A^{*} \in D^{f}$, the formateur receives

$$
W^{f}\left(A^{*}, q\right)-\sum_{\ell \in L} F_{\ell}^{*}=E U^{f}\left(x^{A^{*}}, A^{*} ; q\right)+\sum_{\ell \in L}\left(B_{\ell}^{* A^{*}}-F_{\ell}^{*}\right)
$$


If $A^{*}=\emptyset$, the formateur receives

$$
\alpha_{f} u_{f}(q)+\sum_{\ell \in L} \max \left\{v_{\ell}(q)-F_{\ell}^{*}, 0\right\}
$$

3. Coalition partners $j \in A^{*} \backslash f$ receive $E U^{j}\left(x^{A^{*}}, A^{*} ; q\right)$.

4. Non-coalition members $j \notin A^{*}$ receive $\alpha_{j} u_{j}\left(x^{A^{*}}\right)$.

The formateur's utilities for the subgames depend on his share of contributions to induce bargaining failure $\delta_{f}^{* A} \sum_{\ell \in L} \max \left\{v_{\ell}(q)-B_{\ell}^{* A}, 0\right\}$. For subgame equilibria in which those contributions are made, the formateur's choice of a coalition can be affected. For some subgame equilibrium selections the formateur chooses the status quo, so lobbying can preserve the status quo and result in gridlock even though an alternative coalition yields greater aggregate utility. This is illustrated in Section 5 .

The equilibrium coalition is not necessarily the coalition with the greatest policy utility for two reasons. First, the lobbies' contributions in support of the status quo in the subgames can influence the choice of a coalition in the first stage, and those contributions are costless to the lobbies but costly to the formateur when the contributions are offered to the coalition partners. Second, the formateur only internalizes an $\frac{1}{|A|}$ share of the total surplus from the legislative bargaining.

When all of the contributions in favor of bargaining failure are made to the formateur in every subgame, or $\delta_{f}^{* A}=1, \forall A \in D^{f}$, government failure $\emptyset$ is never chosen by the formateur in the initial stage of the game, as indicated in the following corollary.

Corollary 2 In any truthful equilibrium of the full game in which $\delta_{f}^{* A}=1$ for some $A \in D^{f}$, the formateur selects some coalition $A \in D^{f}$ in the coalition selection stage.

Proof: The corollary holds if $W^{f}(A, q) \geq W^{f}(\emptyset, q)$, for some $A \in D^{f}$; i.e., the aggregate utility to the formateur and the lobbies is greater from selecting some $A$ than from selecting $\emptyset$. When $\delta_{f}^{* A}=1$,

$$
\begin{aligned}
W^{f}(A, q) & =E U^{f}\left(x^{A}, A, q\right)+\sum_{\ell \in L} B_{\ell}^{* A} \\
& =\frac{1}{|A|} R\left(x^{A} ; A, q\right)+\alpha_{f} u_{f}(q)+\sum_{\ell \in L} \max \left\{v_{\ell}(q)-B_{\ell}^{* A}, 0\right\}+\sum_{\ell \in L} B_{\ell}^{* A},
\end{aligned}
$$

and therefore

$$
\begin{aligned}
W^{f}(A, q)-W^{f}(\emptyset, q) & =\frac{1}{|A|} R\left(x^{A} ; A, q\right)+\sum_{\ell \in L}\left(\max \left\{v_{\ell}(q)-B_{\ell}^{* A}, 0\right\}-\left(v_{\ell}(q)-B_{\ell}^{* A}\right)\right) \\
& =\frac{1}{|A|} R\left(x^{A} ; A, q\right)+\sum_{\ell \in L} \max \left\{B_{\ell}^{* A}-v_{\ell}(q), 0\right\} \geq 0
\end{aligned}
$$


since $R\left(x^{A} ; A, q\right) \geq 0$ and $\max \left\{B_{\ell}^{* A}-v_{\ell}(q), 0\right\} \geq 0$.

A coalition $A \in D^{f}$ is also selected when the status quo is sufficiently far from the preferences of the lobbies.

Corollary 3 In any truthful equilibrium of the full game in which $v_{\ell}(q) \leq B_{\ell}^{* A}, \forall \ell \in L, A \in D^{f}$, the formateur selects a coalition $A \in D^{f}$ in the coalition selection stage.

Proof: Since $v_{\ell}(q) \leq B_{\ell}^{* A}, C_{\ell j}\left(q^{o} ; A, q\right)=0$ and

$$
W^{f}(A, q)=\frac{1}{|A|} R\left(x^{A} ; A, q\right)+\alpha_{f} u_{f}(q)+\sum_{\ell \in L} B_{\ell}^{* A} .
$$

Then,

$$
W^{f}(A, q)-W^{f}(\emptyset, q)=\frac{1}{|A|} R\left(x^{A} ; A, q\right)+\sum_{\ell \in L}\left(B_{\ell}^{* A}-v_{\ell}(q)\right) \geq 0
$$

\subsection{The Pattern of Contributions}

The equilibrium payoff $F_{\ell}^{*}$ of lobby $\ell$ is no greater than the payoff $B_{\ell}^{* A^{*}}$ in the subgame commencing with the selection of $A^{*}$. This means that a lobby that in equilibrium makes no offer $H_{\ell}^{*}(\emptyset, q)=0$ against the selection of a coalition also makes no offer to induce bargaining failure and preserve the status quo in the subgame commencing with the selection of $A^{*}$. That is,

$$
H_{\ell}^{*}(\emptyset, q)=0 \Longrightarrow F_{\ell}^{*} \geq v_{\ell}(q) \Longrightarrow B_{\ell}^{* A^{*}} \geq v_{\ell}(q) \Longrightarrow \max \left\{v_{\ell}(q)-B_{\ell}^{* A^{*}}, 0\right\}=C_{\ell}^{*}\left(q^{o} ; A^{*}, q\right)=0 .
$$

However, a lobby that prefers the status quo to the equilibrium policy $x^{A^{*}}$ in the subgame and hence offers positive (truthful) contributions $C_{\ell}^{*}\left(q^{o} ; A^{*}, q\right)>0$ to induce bargaining failure makes even (weakly) larger contributions to prevent coalition formation in the first stage of the game. That is,

$$
0<C_{\ell}^{*}\left(q^{o} ; A^{*}, q\right)=v_{\ell}(q)-B_{\ell}^{* A^{*}} \leq v_{\ell}(q)-F_{\ell}^{*}=H_{\ell}^{*}(\emptyset, q)
$$

If $C_{\ell}^{*}\left(q^{o} ; A^{*}, q\right)<H_{\ell}^{*}(\emptyset, q)$, then $F_{\ell}^{*}<B_{\ell}^{*} A^{*}$, which implies that the lobby offers strictly positive contributions in favor of the equilibrium coalition $A^{*}$ in the bidding up stage. These contributions support $A^{*}$ against the selection of another coalition.

The contribution $H_{\ell}^{*}(\emptyset, q)$ is intended to elicit $\emptyset$ from the formateur rather than $A^{*}$, and it may be the case that $H_{\ell}^{*}(\emptyset, q)>0$ but $C_{\ell}^{*}\left(q^{o} ; A^{*}, q\right)=0$. That is, the lobby offers positive contributions to prevent the equilibrium coalition from being formed in the first stage but once chosen does not make offers to defeat it in the subgame. In contrast, if a lobby does not offer a contribution against coalition formation $\left(H_{\ell}^{*}(\emptyset, q)=0\right)$ 
but does make a positive offer $H_{\ell}^{*}(A, q)>0$ to elicit a particular (not necessarily equilibrium) coalition $A$, then $C_{\ell}^{*}\left(q^{o} ; A, q\right)=0$, since $B_{\ell}^{* A}>F_{\ell}^{*} \geq v_{\ell}(q)$. So, a lobby that supports the selection of $A$ and does not support $\emptyset$ in the first lobbying stage makes no contribution to defeat coalition $A$ in the subgame following its selection.

\section{Example}

\subsection{The Set-Up}

This section presents an example to illustrate the characterization of (truthful) equilibria for the full game and the influence of lobbies on coalition and policy choice. The example also illustrates the bidding up in the first lobbying stage and the role of equilibrium selection in the equilibria of the full game. To illustrate the effects of lobbying on coalition choice and legislative bargaining, the example is the bargaining game in Baron and Diermeier (2001) absent the election. The game includes a legislature $P=\{1,2,3\}$ and three lobbies $L=\{1,2,3\}$ with the policy set $X \subset \Re^{2}$, and assume that $\bar{S}=0$. The legislators have quadratic utility functions for policy, where the ideal policies $z^{i}$ are the vertices of an equilateral triangle $z^{1}=(0,0), z^{2}=(1,0), z^{3}=\left(\frac{1}{2}, \frac{\sqrt{3}}{2}\right)$. This specification treats the legislators symmetrically, so no coalition is more likely to form than any other due to an alignment of legislators' preferences. Hence, there is no legislator preference-based explanation for one coalition selection rather than another. This facilitates the identification of the influence of the lobbies. The policy preferences of the legislators are represented by quadratic preference functions

$$
\begin{gathered}
u_{1}(x)=-x_{1}^{2}-x_{2}^{2} \\
u_{2}(x)=2 x_{1}-x_{1}^{2}-x_{2}^{2} \\
u_{3}(x)=x_{1}-x_{1}^{2}+\sqrt{3} x_{2}-x_{2}^{2},
\end{gathered}
$$

and assume that $\alpha_{i}=1, i=1,2,3$. Let legislator 1 be the formateur.

The lobbies may be thought of as interest groups with more extreme preferences than the legislators. The utility functions of the lobbies are specified as

$$
\begin{gathered}
v_{1}(x)=-2 x_{1}-x_{1}^{2}-x_{2}^{2} \\
v_{2}(x)=4 x_{1}-x_{1}^{2}-x_{2}^{2} \\
v_{3}(x)=x_{1}-x_{1}^{2}+\sqrt{3} x_{2}-x_{2}^{2},
\end{gathered}
$$


which imply ideal policies given by $y^{1}=(-1,0), y^{2}=(2,0), y^{3}=\left(\frac{1}{2}, \frac{\sqrt{3}}{2}\right)$. Lobbies 1 and 2 have a stronger incentive to influence policy than does lobby 3 , since their ideal points are more extreme relative to the preferences of the legislators.

\subsection{Legislative Bargaining and Policy Lobbying Equilibria}

To compute the set of truthful equilibrium in each subgame corresponding to the choice of proto-coalition $A \in D^{f}$, we apply Proposition 1 .

\subsubsection{Subgame with Coalition $\mathbf{A}=\{12\}$}

The optimal policies $x_{-J}^{12}$ for the coalition $\{12\}$ and the lobbies not in $J$ for each subset $J \in 2^{L}$ of lobbies are:

$$
\begin{array}{lllr}
x^{12}=\left(\frac{1}{2}, \frac{\sqrt{3}}{10}\right) & x_{-1}^{12}=\left(\frac{7}{8}, \frac{\sqrt{3}}{8}\right) & x_{-2}^{12}=\left(\frac{1}{8}, \frac{\sqrt{3}}{8}\right) & x_{-3}^{12}=\left(\frac{1}{2}, 0\right) \\
x_{-12}^{12}=\left(\frac{1}{2}, \frac{\sqrt{3}}{6}\right) & x_{-23}^{12}=(0,0) & x_{-13}^{12}=(1,0) & x_{-123}^{12}=\left(\frac{1}{2}, 0\right) .
\end{array}
$$

and

$$
Z\left(x^{12},\{12\}\right)=u_{1}\left(x^{12}\right)+u_{2}\left(x^{12}\right)+\sum_{L \in L} v_{\ell}\left(x^{12}\right)=7 / 5 .
$$

The $2^{|\bar{L}|}-1=7$ inequalities characterizing the feasible payoff set for the lobbies from Proposition 1 then are:

$$
\begin{array}{cc}
\text { (1) } & B_{1}^{* 12} \leq Z\left(x^{12},\{12\}\right)-Z_{-1}\left(x_{-1}^{12},\{12\}\right)=7 / 5-13 / 4=-37 / 20 \\
\text { (2) } & B_{2}^{* 12} \leq Z\left(x^{12},\{12\}\right)-Z_{-2}\left(x_{-2}^{12},\{12\}\right)=7 / 5-1 / 4=23 / 20 \\
\text { (3) } & B_{3}^{* 12} \leq Z\left(x^{12},\{12\}\right)-Z_{-3}\left(x_{-3}^{12},\{12\}\right)=7 / 5-1=2 / 5 \\
\text { (4) } & B_{1}^{* 12}+B_{2}^{* 12} \leq Z\left(x^{12},\{12\}\right)-Z_{-12}\left(x_{-12}^{12},\{12\}\right)=7 / 5-1=2 / 5 \\
\text { (5) } & B_{2}^{* 12}+B_{3}^{* 12} \leq Z\left(x^{12},\{12\}\right)-Z_{-23}\left(x_{-23}^{12},\{12\}\right)=7 / 5-0=7 / 5 \\
\text { (6) } & B_{1}^{* 12}+B_{3}^{* 12} \leq Z\left(x^{12},\{12\}\right)-Z_{-13}\left(x_{-13}^{12},\{12\}\right)=7 / 5-3=-8 / 5 \\
\text { (7) } & B_{1}^{* 12}+B_{2}^{* 12}+B_{3}^{* 12} \leq Z\left(x^{12},\{12\}\right)-Z_{-123}\left(x_{-123}^{12},\{12\}\right)=7 / 5-1 / 2=9 / 10 .
\end{array}
$$

Let $\bar{B}_{\ell}^{A}$ denote "candidate" equilibrium constants satisfying (1)-(3) as equalities. Checking constraints (4)-(6) at these values yields

$$
\begin{array}{ll}
2 / 5-\left(\bar{B}_{1}^{12}+\bar{B}_{2}^{12}\right)=2 / 5-(-37 / 20+23 / 20)=11 / 10 & (\text { HOLDS }) \\
7 / 5-\left(\bar{B}_{2}^{12}+\bar{B}_{3}^{12}\right)-7 / 5=7 / 5-(23 / 20+2 / 5)=-3 / 20 & (\text { FAILS }) \\
-8 / 5-\left(\bar{B}_{1}^{12}+\bar{B}_{3}^{12}\right)=-8 / 5-(-37 / 20+2 / 5)=-3 / 20 & \text { (FAILS) }
\end{array}
$$

Constraints (5) and (6) fail at the candidate constants, and the constants, which equal the utilities of the 
lobbies, must be revised downward. This indicates that there are complementarities between the interests of the lobbies. Constraint (5) binds because jointly considering the interests of lobbies 2 and 3 imposes a greater externality than considering each in isolation, and the same is true for lobbies 1 and 3 , so (6) binds.

The full set of equilibrium constants is the Pareto frontier of the constrained payoff set above, and the Pareto frontier has both constraints (5) and (6) binding, which yields the utilities

$$
\begin{aligned}
& B_{1}^{* 12}=-37 / 20-3 / 20+\varepsilon_{12}=-2+\varepsilon_{12} \\
& B_{2}^{* 12}=23 / 20-3 / 20+\varepsilon_{12}=1+\varepsilon_{12} \\
& B_{3}^{* 12}=\quad 2 / 5-\varepsilon_{12},
\end{aligned}
$$

where $\varepsilon_{12} \in\left[0, \frac{3}{20}\right]$. There is thus a continuum of equilibria determined by which lobbies share the burden of satisfying the constraints in (5) and (6). That is, in (5) either or both lobbies 2 and 3 could raise their contribution schedules (lower their constants) so that the proposer does not ignore their interests. The equilibria are not payoff equivalent for the proposer, however, since it is more efficient for lobby 3 to raise its contribution schedule because this helps meet both constraints (5) and (6).

The formateur's equilibrium utility when selecting coalition $A=\{12\}$ is

$$
\begin{aligned}
E U^{f}\left(x^{12},\{12\}, q\right)= & \frac{1}{2}\left(Z\left(x^{12},\{12\}\right)-u_{1}(q)-u_{2}(q)\right)+u_{1}(q)-\frac{1}{2} \sum_{\ell \in L} B_{\ell}^{* 12} \\
& +\left(\delta_{f}^{* A}-\frac{1}{|A|}\right) \sum_{\ell \in L} \max \left\{v_{\ell}(q)-B_{\ell}^{A}, 0\right\} \\
= & 1+\frac{1}{2}\left(u_{1}(q)-u_{2}(q)\right)-\frac{1}{2} \varepsilon_{12}+\left(\delta_{f}^{* A}-\frac{1}{2}\right) \sum_{\ell \in L} \max \left\{v_{\ell}(q)-B_{\ell}^{A}, 0\right\} .
\end{aligned}
$$

The utility of the formateur depends not only on $\varepsilon_{12}$ but also on the proportion $\delta_{f}^{A}$ of the lobbies' aggregate contributions offered to induce bargaining failure that go to the formateur, since these determine part of his reservation value in the bargaining game. The set of feasible utilities $E U^{f}\left(x^{12},\{12\}, q\right)$ for the formateur in the policy lobbying game are given by

$$
\begin{aligned}
& E U^{f}\left(x^{12},\{12\}, q\right) \in \\
& \left\{\begin{array}{l}
1+\frac{1}{2}\left(u_{1}(q)+u_{2}(q)\right)-\frac{1}{2} \varepsilon_{12} \\
+\left(\delta_{f}^{* 12}-\frac{1}{2}\right)\left(\max \left\{v_{1}(q)+2-\varepsilon_{12}, 0\right\}+\max \left\{v_{2}(q)-1-\varepsilon_{12}, 0\right\}+\max \left\{v_{3}(q)-\frac{2}{5}+\varepsilon_{12}, 0\right\}\right) \\
\quad \text { such that } \delta_{f}^{* 12} \in[0,1] \text { and } \varepsilon_{12} \in\left[0, \frac{3}{20}\right] .
\end{array}\right.
\end{aligned}
$$

The continuation value $E U^{f}\left(x^{12},\{12\}, q\right)$ of the formateur thus depends on two selections. The first is how the lobbies' contribution schedules meet the conditions that induce the prospective coalition to take all their interests into account from Proposition 1, or the $\varepsilon_{12}$ term. The second is the extent to which the lobbies make contributions to the formateur in support of bargaining failure, or $\delta_{\ell}^{* 12}$, which increases her 
bargaining strength. Conversely, a shift of status quo contributions to a legislator other than the formateur coalition makes coalition $A=\{12\}$ less attractive to the formateur in the coalition selection stage of the game.

\subsubsection{Subgame with Coalition $\mathbf{A}=\{13\}$}

For the subgame in which the formateur chooses $A=\{13\}$ in the first stage of the game, the policy is $x^{13}=\left(\frac{2}{5}, \frac{\sqrt{3}}{5}\right)$. The equilibrium constants are

$$
\begin{aligned}
& B_{1}^{* 13}=\quad-\frac{8}{5} \\
& B_{2}^{* 13}=\frac{13}{20}-\frac{7}{30}+\varepsilon_{13}=\frac{5}{12}+\varepsilon_{13} \\
& B_{3}^{* 13}=\quad \frac{13}{20}-\varepsilon_{13},
\end{aligned}
$$

where $\varepsilon_{13} \in\left[0, \frac{7}{30}\right]$ and the derivation is presented in Appendix B.

The formateur's set of equilibrium payoffs does not depend on the equilibrium selection $\varepsilon_{13}$, since

$$
E U^{f}\left(x^{13},\{13\}, q\right)=\frac{29}{30}+\frac{1}{2}\left(u_{1}(q)-u_{3}(q)\right)+\left(\delta_{f}^{* 13}-\frac{1}{2}\right) \sum_{\ell \in L} \max \left\{v_{\ell}(q)-B_{\ell}^{* 13}, 0\right\} .
$$

The set of feasible utilities $E U^{f}\left(x^{13},\{13\}, q\right)$ for the formateur in the policy lobbying game are given by

$$
\begin{aligned}
& E U^{f}\left(x^{13},\{13\}, q\right) \in \\
& \left\{\begin{array}{l}
\frac{29}{30}+\frac{1}{2}\left(u_{1}(q)-u_{3}(q)\right) \\
+\left(\delta_{1}^{* 13}-\frac{1}{2}\right) \cdot\left(\max \left\{v_{1}(q)+\frac{8}{5}, 0\right\}+\max \left\{v_{2}(q)-\frac{5}{12}-\varepsilon_{13}, 0\right\}+\max \left\{v_{3}(q)-\frac{13}{20}+\varepsilon_{13}, 0\right\}\right) \\
\quad \text { such that } \delta_{f}^{* 13} \in[0,1] \text { and } \varepsilon_{13} \in\left[0, \frac{7}{30}\right] .
\end{array}\right.
\end{aligned}
$$

\subsubsection{Subgame with Coalition $\mathbf{A}=\{123\}$}

For the subgame in which the formateur chooses $A=\{123\}$ in the first stage of the game, the policy is $x^{123}=\left(\frac{1}{2}, \frac{1}{2 \sqrt{3}}\right)$. The equilibrium constants are

$$
\begin{aligned}
& B_{1}^{* 123}=-9 / 5-1 / 20+\varepsilon_{123}=-37 / 20+\varepsilon_{123} \\
& B_{2}^{* 123}=6 / 5-1 / 20+\varepsilon_{123}=23 / 20+\varepsilon_{123} \\
& B_{3}^{* 123}=\quad 3 / 5-\varepsilon_{123},
\end{aligned}
$$

where $\varepsilon_{123} \in\left[0, \frac{1}{20}\right]$ and the derivation is presented in Appendix B. 
The set of feasible utilities $E U^{f}\left(x^{123},\{123\}, q\right)$ for the formateur are

$$
\begin{aligned}
& E U^{f}\left(x^{123},\{123\}, q\right) \in \\
& \left\{\begin{array}{l}
\frac{7}{10}+\frac{1}{3}\left(2 u_{1}(q)-u_{2}(q)-u_{3}(q)-\varepsilon_{123}\right) \\
+\delta_{1}^{* 123}\left(\max \left\{v_{\ell}(q)+\frac{37}{20}-\varepsilon_{123}, 0\right\}+\max \left\{v_{\ell}(q)-\frac{23}{20}-\varepsilon_{123}, 0\right\}+\max \left\{v_{\ell}(q)-\frac{3}{5}+\varepsilon_{123}, 0\right\}\right) \\
\quad \text { such that } \delta_{f}^{* 123} \in[0,1] \text { and } \varepsilon_{123} \in\left[0, \frac{1}{20}\right] .
\end{array}\right.
\end{aligned}
$$

\subsection{Bidding Up and Coalition Choice (First Stage Equilibrium)}

The characterization of the equilibria of the first stage of the full game depends on the formateur's utilities in each of the subgames, which depend on the selection of $\varepsilon_{12}, \varepsilon_{13}$, and $\varepsilon_{123}$ and on how the lobbies allocate their contribution offers in favor of the status quo. This section makes the specific assumption that in every subgame the formateur receives a $\frac{1}{|A|}$ share of the contribution offers in favor of the status quo; i.e., $\delta_{f}^{* A}=\frac{1}{|A|}, \forall A \in D^{f}$. This assumption is equivalent to the lobbies randomly allocating among the coalition members their contribution offers in support of the status quo. This assumption is not unreasonable, since those offers do not affect the legislative bargaining outcome and hence are never paid. Other allocations of the contributions in support of legislative bargaining failure are considered below and illustrated in figures.

The aggregate payoffs to the formateur and the lobbies is

$$
W^{f}(A, q)=u_{f}\left(q^{o}\right)+\frac{1}{|A|}\left(Z\left(x^{A}, A\right)-\sum_{j \in A} u_{j}(q)\right)+\left(\frac{|A|-1}{|A|}\right) \sum_{\ell \in L} B_{\ell}^{* A},
$$

which can be evaluated as

$$
W^{f}(A, q)= \begin{cases}2 / 5+\frac{1}{2}\left(u_{1}(q)-u_{2}(q)\right) & \text { for } A=\{12\} \\ 13 / 30+\frac{1}{2}\left(u_{1}(q)-u_{3}(q)\right) & \text { for } A=\{13\} \\ 3 / 5+\frac{1}{3}\left(2 u_{1}(q)-u_{2}(q)-u_{3}(q)\right) & \text { for } A=\{123\} \\ u_{f}(q)+\sum_{L} v_{\ell}(q) & \text { for } A=\emptyset .\end{cases}
$$

This expression can be used to identify the sets of status quos such that the formateur would choose a particular coalition. Consider first status quos that are sufficiently "far away" that $A=\emptyset$ is not optimal. Then, the sets $Q^{A}$ of status quos such that $A$ is an equilibrium are

$$
\begin{aligned}
Q^{12} & \equiv\left\{q \mid u_{3}(q) \geq \max \left\{\frac{3}{5}+\frac{1}{2}\left(u_{1}(q)+u_{2}(q)\right), \frac{1}{15}+u_{2}(q)\right\}\right\} \\
Q^{13} & \equiv\left\{q \mid u_{2}(q) \geq \max \left\{\frac{1}{2}+\frac{1}{2}\left(u_{1}(q)+u_{3}(q)\right), u_{3}(q)-\frac{1}{15}\right\}\right\} \\
Q^{123} & \equiv\left\{q \mid \frac{1}{2}+\frac{1}{2}\left(u_{1}(q)+u_{3}(q)\right) \geq u_{2}(q) \geq-u_{1}(q)+2 u_{3}(q)-\frac{6}{5}\right\}
\end{aligned}
$$


These sets correspond to the intuition presented earlier for the legislative bargaining stage. If the status quo is far from the ideal point of legislator 2 and closer to the ideal point of legislator 3 , legislator 2 is in the weaker bargaining position and hence the formateur chooses $A^{*}=\{12\}$. That is, $q \in Q^{12}$. Conversely, if $u_{3}(q)$ is small relative to $u_{2}(q)$, legislator 3 is in the weaker bargaining position; i.e., $q \in Q^{13}$ and $A^{*}=\{13\}$. If the status quo is far from the ideal points of both legislators 2 and 3 and is on the side of the policy space closest to her ideal point, the formateur $(f=1)$ chooses $A^{*}=\{123\}$. A status quo that is on the opposite side of the policy space from the formateur does not lead to the choice of $A=\{123\}$, since the formateur recognizes that for such a status quo she will be disadvantaged relative to her coalition partners in the legislative bargaining. Instead, she prefers a minimal winning coalition in which both she and her coalition partner are disadvantaged by the status quo, since her weak bargaining position will be exploited by her coalition partner with probability $\frac{1}{2}$, whereas with a consensus coalition her weak bargaining position will be exploited with probability $\frac{2}{3}$. In contrast, a status quo that is close to the ideal points of the lobbies allows the lobbies to induce the formateur to choose $A^{*}=\emptyset$. These four regions are illustrated in Figure 1.

The characterization of the equilibrium coalition selection is straightforward, but characterization of the specific "bidding up" contributions offers and equilibrium payoffs is considerably more complex, since they depend on the specific equilibrium selections for how the constraints are met in the subsequent subgames in addition to how the contributions in support of the status quo are allocated among the coalition members. Characterizing the full set of equilibria provides little intuition beyond that which can be attained from a particular case. The case considered is that in which $\delta_{f}^{* A}=\frac{1}{|A|}, \forall A \in D^{f}$, and $\varepsilon_{A}=0, \forall A \in D^{f}$.

The equilibrium expected utilities of the lobbies in the subgames where a coalition $A \in D^{f}$ is selected are:

$\begin{array}{cccc}A & B_{1}^{* A} & B_{2}^{* A} & B_{3}^{* A} \\ \{12\} & -2 & 1 & \frac{2}{5} \\ \{13\} & -\frac{8}{5} & \frac{5}{12} & \frac{13}{20} \\ \{123\} & -\frac{37}{20} & \frac{23}{20} & \frac{3}{5}\end{array}$

In the subgame in which no coalition $A=\emptyset$ is selected the utilities are simply the policy utilities from the status quo. To characterize an equilibrium, it is necessary to have a specific status quo, which is taken to be $q=(1,3 / 4)$. This status quo is closer to legislator 3's ideal point than to legislator 2's ideal point, and the equilibrium coalition is $A^{*}=\{12\}$, as is evident in Figure 1. For this equilibrium selection and this status quo, $A_{-J}^{*}=\{12\}$, for $J=\{3\},\{13\},\{123\}, A_{-J}^{*}=\{13\}$ for $J=\{2\},\{12\},\{23\}$, and $A_{-J}^{*}=\emptyset$ for $J=\{1\}$.

To characterize the equilibrium to the bidding up (first stage) game, substitute the optimal coalitions 
into the bidding up constraints in Proposition 2 for $A=\{12\}$, which yields

(1) $\quad F_{1} \leq W^{f}(\{12\}, q)-W^{f}(\emptyset, q)=-2.2115$

(2) $F_{2} \leq W^{f}(\{12\}, q)-W_{-2}^{f}(\{13\}, q)=.5329$

$$
F_{3} \leq B_{3}^{* 12}=\frac{2}{5}
$$

(4) $F_{1}+F_{2} \leq W^{f}(\{12\}, q)-W_{-12}^{f}(\{13\}, q)=-1.0672$

(5) $\quad F_{2}+F_{3} \leq W^{f}(\{12\}, q)-W_{-23}^{f}(\{13\}, q)=1.1829$

$$
F_{1}+F_{3} \leq B_{1}^{* 12}+B_{3}^{* 12}=-\frac{8}{5}
$$

$$
F_{1}+F_{2}+F_{3} \leq B_{1}^{* 12}+B_{2}^{* 12}+B_{3}^{* 12}=-\frac{3}{5} .
$$

With the constraints (1)-(3) binding the other 4 constraints are satisfied, so there are no complementarities between the interests of the lobbies over coalitions. In this equilibrium, the lobbies have unique equilibrium payoffs over the full game given by

$$
F_{1}^{*}=-2.2115, \quad F_{2}^{*}=0.5329, \quad F_{3}^{*}=\frac{2}{5} .
$$

The bidding up in the first stage of the game to influence the selection of the coalition is characterized by lobbies 1 and 2 having net payoff vectors $F_{1}^{*}$ and $F_{2}^{*}$ less than $B_{1}^{* 12}$ and $B_{2}^{* 12}$, since both must make contributions to maintain the equilibrium coalition $\{12\}$. Lobby 1 prefers to do so because if it did not, the formateur would select no coalition $A=\emptyset$ and allow the status quo to prevail. Lobby 2 prefers to do so because otherwise the formateur would switch to $A=\{13\}$. Lobby 3 has utility $F_{3}^{*}=B_{3}^{* 12}$, and offers no contributions in support of $A=\{12\}$ in the first stage of the game.

The "bidding up" contributions in the first stage of the game are

$$
H_{\ell}^{*}(A, q)=\max \left\{B_{\ell}^{* A}-F_{\ell}^{*}, 0\right\}
$$

so for the example

$$
B_{\ell}^{* A}-F_{\ell}^{*}=\left\{\begin{array}{cccc} 
& \ell=1 & \ell=2 & \ell=3 \\
A=\{12\} & B_{1}^{* 12}-F_{1}^{*} & B_{2}^{* 12}-F_{2}^{*} & B_{3}^{* 12}-B_{3}^{* 12} \\
A=\{13\} & B_{1}^{* 13}-F_{1}^{*} & B_{2}^{* 13}-F_{2}^{*} & B_{3}^{* 13}-B_{3}^{* 12} \\
A=\{123\} & B_{1}^{* 123}-F_{1}^{*} & B_{2}^{* 123}-F_{2}^{*} & B_{3}^{* 123}-B_{3}^{* 12} \\
A=\emptyset & v_{\ell}(q)-F_{1}^{*} & v_{\ell}(q)-F_{2}^{*} & v_{\ell}(q)-B_{3}^{* 12}
\end{array}\right.
$$


The contributions offered in support of the coalitions $A \in D^{f} \cup \emptyset$ are then

$$
H_{\ell}^{*}(A, q)=\left\{\begin{array}{cccc} 
& \ell=1 & \ell=2 & \ell=3 \\
A=\{12\} & 0.2115 & 0.4671 & 0 \\
A=\{13\} & 0.6115 & 0 & 1 / 4 \\
A=\{123\} & 0.3615 & 0.6171 & 1 / 5 \\
A=\emptyset & 0 & 1.9047 & 0.3365 .
\end{array}\right.
$$

In this example the lobbies can be better or worse off compared to a ban on lobbying. They can be worse off because the lobbies have opposing preferences, and hence their influence activities are counteractive. Lobbies 2 and 3 prefer the status quo to $A^{*}=\{12\}$, whereas lobby 1 prefers the equilibrium coalition. Note that lobby 2 offers a contribution in favor of the selection $A=\emptyset$ and also offers a contribution in support of $A=\{12\}$. The former is intended to induce the formateur to let the status quo continue, whereas the latter is made to protect the selection of $A=\{12\}$ against the selection of another coalition in $D^{f}$. Lobby 1 offers contributions in support of every coalition including the equilibrium coalition $\{12\}$ in order to prevent the selection of the status quo, since he is the most disadvantaged by it. Lobby 3 offers contributions in support of $A=\{13\}$ and $A=\{123\}$, and lobby 2 also offers contributions in support of $A=\{123\}$ but not for $A=\{13\}$.

With the selection of $A^{*}$ the formateur receives $E U^{f}\left(x^{12},\{12\}, q\right)+H_{1}(\{12\}, q)+H_{2}(\{12\}, q)=0.6787$. Because lobby 1 contributes to prevent the selection of no coalition $\emptyset$, his minimum contributions to maintain influence in the coalition selection stage leave the formateur indifferent between choosing the equilibrium coalition $\{12\}$ and choosing $\emptyset$, or

$$
u_{1}(q)+H_{2}(\emptyset, q)+H_{3}(\emptyset, q)=-\frac{25}{16}+1.9047+.3365=0.6787 .
$$

Lobby 2's contributions similarly leave the formateur indifferent between choosing the equilibrium coalition $\{12\}$ and choosing $\{13\}$.

\subsubsection{Alternative Selections of the Contributions in Support of the Status Quo}

The maintained assumption in the above characterization of a full equilibrium is based on a uniform allocation among the legislators of the contributions in the subgames in support of the status quo. To illustrate the import of this allocation on the equilibrium coalition, consider first the case in which all of the contributions in support of the status quo are made to the formateur; i.e., $\delta_{f}^{* A}=1, \forall A \in D^{f}$, again using the example of $q=(1,3 / 4)$. This allocation increases the utility of the formateur, since her reservation value is greater. 
The aggregate utilities $W^{f}(A, q)$ are then

$$
W^{f}(\{12\}, q)=0.2870, \quad W^{f}(\{13\}, q)=0.3375, \quad W^{f}(\{123\}, q)=0.1163, \quad W^{f}(\emptyset, q)=-1.95096 .
$$

The formateur selects the coalition $A^{*}=\{13\}$, as is evident in Figure 2. The set of status quos such that the formateur chooses no coalition is now empty, so the status quo never prevails in equilibrium when in the subgames all the contributions in support of the status quo are made to the formateur.

The other polar case is that in which none of the contributions in support of the status quo are made to the formateur; i.e., $\delta_{f}^{* A}=0, \forall A \in D^{f}$. The aggregate utilities are then

$W^{f}(\{12\}, q)=-1.4870, \quad W^{f}(\{13\}, q)=-1.7699, \quad W^{f}(\{123\}, q)=-1.3077, \quad W^{f}(\emptyset, q)=-1.9510$.

The utilities for the subgames are lower because in the legislative bargaining the reservation value of the formateur is lower. In this case the formateur chooses the consensus coalition $A^{*}=\{123\}$. The reason is that the lobbies make fewer aggregate contributions in favor of the status quo when the consensus coalition is selected, since it enacts a centrist policy. This makes the consensus coalition more attractive when status quo contributions are directed to the formateur's coalition partners, relative to when they are directed to the formateur. The set of status quos for which a consensus coalition is chosen by the formateur is therefore larger, as illustrated in Figure 3. In addition, the set of status quos such that no coalition $A^{*}=\emptyset$ is chosen is larger than the set in Figure 1.

\subsubsection{Lobby Influence}

The influence of the lobbies can be identified by comparing the formateur's coalition selection in the absence of first-stage lobbying with the selections identified in Figures 1-3. Figure 4 identifies coalition selection without first-stage lobbying for $\delta_{f}^{* A}=\frac{1}{|A|}, \forall A \in D^{f}$, and comparing it with Figure 1 indicates that lobbying induces the formateur to choose a consensus coalition for a larger set of $q$ and to preserve the status quo for centrally located $q$. The same is true for $\delta_{f}^{* A}=0, \forall A \in D^{f}$, and for $\delta_{f}^{* A}=1, \forall A \in D^{f}$, as indicated by comparing Figures 5 and 6 with Figures 2 and 3, respectively.

The influence of a lobby's preferences on the equilibrium policy can be characterized locally directly from (10) through a comparative statics exercise, provided that the equilibrium coalition is not affected. More extreme preferences of a lobby thus cause the equilibrium policy to move in the direction of the lobby's ideal point. The legislative bargaining outcome is thus directly responsive to the interests of the lobbies. The equilibrium coalition can also be affected, and to illustrate this, consider the example with $q=(1,3 / 4)$ and let lobby 3 have more extreme preferences with ideal point $y^{3}=(1 / 2,2)$. The more extreme preferences result in both a different coalition and a different policy for that coalition. The formateur chooses $A^{*}=\{13\}$, and 
the corresponding policy is $x^{A^{*}}=(2 / 5,(1 / 10)(4+\sqrt{3}))$. The equilibrium coalition selections are identified in Figures 7-9.

The expected payoffs $B_{\ell}^{* A^{*}}$ of the lobbies are

$$
\begin{array}{cccc}
A & B_{1}^{* A} & B_{2}^{* A} & B_{3}^{* A} \\
\{12\} & -2.0125 & 0.9875 & 1.05 \\
\{13\} & -1.8607 & 0.3893 & 1.6928 \\
\{123\} & -1.9738 & 1.0263 & 1.4690
\end{array}
$$

and the equilibrium net payoff vectors for each $A \in D^{f}$ are unique. The contributions are then obtained from Definition 1. The utilities of the lobbies for the full game are

$$
F_{1}^{*}=-3.1299, \quad F_{2}^{*}=0.3893, \quad F_{3}^{*}=1.1951
$$

which again are unique, and the corresponding contributions in the bidding up stage are:

$$
H_{\ell}^{*}(A, q)=\left\{\begin{array}{cccc} 
& \ell=1 & \ell=2 & \ell=3 \\
A=\{12\} & 1.1174 & 0.5982 & 0 \\
A=\{13\} & 1.2692 & 0 & 0.4977 \\
A=\{123\} & 1.1561 & 0.637 & 0.2740 \\
A=\emptyset & 0 & 2.0482 & 1.2424 .
\end{array}\right.
$$

In the equilibrium lobbies 1 and 3 make positive contribution offers to support the equilibrium coalition $A^{*}=\{13\}$. Lobby 1 offers contributions to prevent a switch to the status quo $A=\emptyset$, since she is disadvantaged by the status quo, and also makes positive offers in support of every coalition $A \in D^{f}$. Lobby 3 offers contributions to prevent a switch to coalition $\{12\}$, the only coalition from which legislator 3 , who has interests most closely aligned with its own, is absent. Lobby 3 also makes its largest offer in favor of the status quo, since that lobby is the most advantaged by it.

\subsubsection{Gridlock}

As illustrated in Figures 1 and 3 for some status quos the formateur chooses no coalition and allows the status quo to persist. As an example, let the status quo be $\hat{q}=\left(\frac{1}{2}, \frac{1}{2 \sqrt{3}}\right)$, which is the centroid of the preferences of the legislators and of the lobbies. The aggregate utilities with $\delta_{f}^{* A}=\frac{1}{|A|}, A \in D^{f}$, are

$$
W^{f}(\{12\}, \hat{q})=-0.1, \quad W^{f}(\{13\}, \hat{q})=-0.0667, \quad W^{f}(\{123\}, \hat{q})=-0.0667,
$$

whereas if the formateur chose $A=\emptyset$, the utility would be

$$
W^{f}(\emptyset, \hat{q})=\frac{2}{3} .
$$


The formateur thus chooses $A^{*}=\emptyset$.

If the formateur were to ignore the lobbies' preferences, she prefers to choose a coalition $A \in D^{f}$ to extract as great a bargaining surplus as possible from her coalition partner(s), and she is approximately indifferent between choosing one of the two minimal winning coalitions $\{12\}$ or $\{13\}$. In expectation, however, the formateur only captures a $\frac{1}{|A|}$ share of the aggregate bargaining surplus from choosing a coalition $A \in D^{f}$, so the preferences of the lobbies have considerable influence at the coalition formation stage. Although gridlock never prevails once a coalition $A \in D^{f}$ is selected, in this example the lobbies can collectively pay

$\frac{19}{60}$ to induce the formateur to select $A=\emptyset$ and maintain the status quo. There exists a continuum of equilibria in which every lobby makes a positive contribution to support $A^{*}=\emptyset .{ }^{17}$

Gridlock refers to the persistence of a "bad" status quo, which can be thought of as a policy outside the Pareto set of the legislators' preferences. Figures 1 and 7 indicate that for $\delta_{f}^{* A}=\frac{1}{|A|}, \forall A \in D^{f}$, some status quo points outside the Pareto set can persist, resulting in gridlock. Figures 3 and 9 indicate that the set of status quos that result in gridlock is larger when $\delta_{f}^{* A}=0, \forall A \in D^{f}$, whereas with $\delta_{f}^{* A}=1, \forall A \in D^{f}$, gridlock does not result as illustrated in Figures 2 and 8. Gridlock results because of lobbying, since in the absence of lobbying the formateur generically chooses a coalition $A \in D^{f}$ resulting in a policy $x^{A} \neq q$, as illustrated in Figures 4-6. Moreover, the policy $x^{A}$ is in the Pareto set of the legislators' preferences. Gridlock is thus due to lobbying.

\subsection{Application: Influence of Lobbies in a Government Formation Context}

Baron and Diermeier present a model of government formation in the absence of interest groups and lobbies, and this section identifies the influence of lobbies on the equilibrium coalitions and policies. In their model legislative bargaining includes transfers as in the model presented here, but the formateur $(f=p=1)$ is the proposer with probability one and makes a take-it-or-leave-it offer to the coalition it selects. ${ }^{18}$ Coalition choice by the formateur is identified by by the sets $Q_{B D}^{A}$ given by

$$
\begin{aligned}
Q_{B D}^{12} & \equiv\left\{q \mid u_{3}(q) \geq \max \left\{\frac{1}{2}, u_{2}(q)\right\}\right\} \\
Q_{B D}^{13} & \equiv\left\{q \mid u_{2}(q) \geq \max \left\{\frac{1}{2}, u_{3}(q)\right\}\right\} \\
Q_{B D}^{123} & \equiv\left\{q \mid \frac{1}{2} \geq \max \left\{u_{2}(q), u_{3}(q)\right\}\right\} .
\end{aligned}
$$

\footnotetext{
${ }^{17}$ One set of equilibrium offers that supports the equilibrium outcome and satisfies the remaining constraints is $H_{1}^{*}(\emptyset, q)=\frac{1}{6}$, $H_{2}^{*}(\emptyset, q)=\frac{1}{10}$, and $H_{3}^{*}(\emptyset, q)=\frac{1}{20}$.

${ }^{18}$ The equilibrium policy also maximizes the aggregate utility of the coalition members.
} 
Figure 10 depicts these sets. The set $Q_{B D}^{12}$ is the intersection of a circle with center $z^{3}$ and radius $\sqrt{\frac{1}{2}}$ and the half-space bounded by the hyperplane equidistant from $z^{2}$ and $z^{3}$. This set has the property that the status quo is farther from legislator 2 than legislator 3, so legislator 2 is a more attractive coalition partner; i.e., he is more disadvantaged in the legislative bargaining than is 3. Similarly, for a status quo $q \in Q_{B D}^{13}$ legislator 3 is the more attractive coalition partner for the formateur. If $q \in Q_{B D}^{123}=\Re^{2} \backslash\left\{Q_{B D}^{12} \cup Q_{B D}^{13}\right\}$, the status quo is sufficiently far from both legislators 2 and 3 that the formateur forms a consensus coalition.

Consider next the addition of lobbies but maintain the assumption that the proposer makes a takeit-or-leave-it offer. In addition, assume that the proposer is the formateur and consider only lobbying in the legislative bargaining stage and not in the coalition selection stage. Adding the lobbies causes the formateur to take into account the interests of the lobbies, and the equilibrium coalitions are identified by the definitions in (19)-(21) with $3 / 5$ replacing $1 / 2 .{ }^{19}$ These sets $\bar{Q}^{A}$ are illustrated in Figure 10. For this example in which lobbies are more extreme than are the legislators, the set $\bar{Q}^{123}$ of status quos that leads to a consensus coalition with lobbying strictly contains the corresponding set in the absence of lobbies. Lobbying by extreme lobbies then leads to consensus governments for a larger set of status quos and correspondingly to minimal winning coalitions for smaller sets of status quos.

The model of legislative bargaining used in this paper distributes legislative bargaining power equally among the members of the selected coalition, and thus in coalition selection the formateur has to take into consideration the bargaining positions of all coalition members. When all lobbies allocate their contributions in support of bargaining failure equally among the coalition members; i.e., $\delta_{f}^{* A}=\frac{1}{|A|}$, the incentive to choose a consensus coalition for status quos on the other side of the Pareto set from the ideal point of the formateur disappears and the formateur prefers a minimal winning coalition, as illustrated in Figure 1. Also, consensus coalitions are chosen for a smaller set of status quos when bargaining power in the legislative bargaining is equally distributed. In addition, the status quo can prevail for centrally located status quos. The theory thus predicts that when the status quo policy is relatively extreme, coalition formation will be successful and result in a relatively central policy. In contrast, if the status quo is centrally located, the policy will persist and no coalition will be chosen. This could be interpreted as a caretaker government in place until an election can be held.

Political institutions differ in the advantages accorded to the formateur, and Figures 2 and 3 provide insight into how coalition choice can vary with that advantage. As the bargaining power of the formateur in the legislative stage increases; i,e., $\delta_{f}^{* A}$ increases, some coalition is chosen for a larger set of status quos and hence a caretaker government is less likely. As Figure 2 indicates, consensus governments result for a larger set of status quos. If the formateur's bargaining power decreases consensus governments form for a

\footnotetext{
${ }^{19}$ Supporting details are available from the authors.
} 
still larger sets of status quos, and in addition the status quo can prevail.

The policy chosen by a coalition is also affected by lobbying, and the policy is always coalition efficient. As the influence of a lobby increases relative to the legislators, the policy is drawn toward the ideal point of the lobby, as considered in Section 5.3.2. More extreme lobbies thus have more influence over policy, and coalition selection can also be affected.

\section{Conclusions}

The governing process represented by the model has two stages: the first involves the identification of a coalition within which bargaining will take place and the second involves legislative bargaining and voting on the coalition and its policy proposal. This could correspond to a parliamentary system in which a formateur identifies a proto-coalition within which to bargain over policy and officeholding benefits with the bargain subject to an installation vote in the parliament. Lobbying tracks the governing process with contributions offered first to influence coalition selection and second to influence the bargaining and voting. The common agency model assumes that utility is transferable between the lobbies and the government, and this assumption is extended by allowing utility to be transferable among the legislators. The model incorporates three features that distinguish it from the standard common agency model with a unitary government decision maker. First, approval of the coalition and policy is by majority rule. Second, to be enacted any proposal must defeat the status quo. Third, lobbying offers can be made both to support the coalition and its policy proposal and to defeat them.

The common agency theory of Bernheim and Whinston provides the framework for characterizing a subgame perfect equilibrium. This involves applying the conditions for a common agency equilibrium to each stage of the governing process. In the legislative bargaining and policy stage the equilibrium has the features of a common agency lobbying equilibrium with a single government decision maker with the exception that in equilibrium the lobbies can offer contributions in support of the status quo. Those contributions are never successful in causing bargaining failure, but they affect the formateur's preferences over coalitions. The lobbies cannot, however, use these contributions strategically to influence coalition formation because strategies are required to be subgame perfect and the lobbies cannot commit ex ante to their offers in the second stage of the governing process.

In the first stage of the governing process the equilibrium can involve bidding up of the lobbies' contribution schedules so as to influence coalition selection. This bidding up can result in no coalition being selected if the lobbies prefer the status quo to the policy that would be chosen if a coalition were formed. Lobbying thus can preserve the status quo and result in gridlock. When a coalition is selected and contribution sched- 
ules are truthful, the equilibrium policy is coalition efficient in the sense that it maximizes the policy utility of the coalition and the lobbies that contribute to it. The equilibrium coalition, however, need not be that which maximizes the policy utility over all coalitions. If a lobby is worse off with a coalition and its policy than with the status quo, the lobby offers contributions to induce the formateur not to choose a coalition and thus allow the status quo to continue.

Multiple equilibria are present even with truthful contribution schedules, since (1) there are multiple configurations of lobbying offers that can support the equilibrium in the legislative bargaining stage and (2) the lobbies can arbitrarily allocate contributions to support the status quo against the coalition and its policy proposal. Neither of these sources of multiplicity affects the equilibrium policy for a given coalition, but the choice of a coalition can be affected. The former affects the contributions in support of the coalition's proposal and hence affects the utility of the formateur. Contribution offers made to the coalition partners to elicit bargaining failure and maintain the status quo reduce the formateur's bargaining power, which makes the coalition less attractive.

The example illustrates the application of the equilibrium characterization to majority rule institutions with a multidimensional policy space. The lobbies have more extreme preferences than the legislators, and contributions are required to be truthful. The set of equilibria is identified, and given particular selections a full equilibrium characterization is presented. Lobbying can be a source of compromise among legislators leading to a consensus government and a centrist policy. This results not because the lobbies prefer a consensus coalition or a centrist policy. Instead, each lobby prefers an extreme policy and lobbies to obtain that policy, but in equilibrium their lobbying is counteractive. Extreme lobbies have strong incentives and make contributions in line with those incentives, but since their interests are opposing, they are in a dilemma and their lobbying can offset the effect of the other lobbies. If all citizens were represented by lobbies, this could be thought of as a pluralism equilibrium in which all interests are politically active and compromise is the result. If only some interests are organized for lobbying, however, and their interests are aligned rather than opposing, the theory indicates that the lobbies can pull policy in their direction and influence coalition selection. 


\section{Appendix A}

\section{Coalition Selection/Bidding Up Game}

The statement of the conditions for an equilibrium is simplified by introducing the functions $M(A)$ : $\left\{D^{f} \cup \emptyset\right\} \rightarrow \Re$ and $N_{\ell}(A):\left\{D^{f} \cup \emptyset\right\} \rightarrow \Re$, which map coalitions $A \in D^{f} \cup \emptyset$ to the players' utility in the subgame in which that coalition in selected. These functions depend explicitly on the equilibrium selection. So for $x^{*} \in X^{*}(A, q)$

$$
\begin{aligned}
& M(A)=\left\{\begin{array}{cc}
\frac{1}{|A|}\left(\sum_{j \in A} \alpha_{j} u_{j}\left(x^{*}\right)+\sum_{\ell \in L} C_{\ell}^{*}\left(x^{*}(A) ; A, q\right)+\bar{S}-\sum_{j \in A} \alpha_{j} u_{j}\left(q^{o}\right)\right) & \text { if } A \in D^{f} \\
\quad+\alpha_{f} u_{f}(q)+\left(\delta_{f}^{* A}-\frac{1}{|A|}\right) \sum_{\ell \in L} C_{\ell}^{*}\left(q^{o} ; A, q\right) & \text { if } A=\emptyset \\
\alpha_{f} u_{f}(q) &
\end{array}\right. \\
& N_{\ell}(A)= \begin{cases}v_{\ell}\left(x^{*}\right)-C_{\ell}^{*}\left(x^{*} ; A, q\right) & \text { if } A \in D^{f} \\
v_{\ell}(q) & \text { if } A=\emptyset .\end{cases}
\end{aligned}
$$

We now state the conditions from common agency theory.

There exists a pure strategy equilibrium of the bidding up game with contributions $H_{\ell}^{*}(A ; q)$ and coalition choice $A^{*} \in D^{f} \cup \emptyset$ if and only if

(i) $H_{\ell}^{*}(A, q) \geq 0, \forall \ell \in L, A \in D^{f} \cup \emptyset$

(ii) $A^{*} \in \arg \max _{A \in\left\{D^{f} \cup \emptyset\right\}}\left\{M(A)+\sum_{\ell \in L} H_{\ell}^{*}(A, q)\right\}$

(iii) For every $k \in L, A^{*} \in \arg \max _{A \in\left\{D^{f} \cup \emptyset\right\}}\left\{N_{k}(A)+M(A)+\sum_{\ell \in L \backslash k} H_{\ell}^{*}(A ; q)\right\}$.

(iv) For every $k \in L$ there exists $\hat{A}^{k}$ satisfying property (ii) with $H_{k}^{*}\left(\hat{A}^{k} ; q\right)=0$.

\section{Appendix B}

\section{Subgame with Coalition $\mathbf{A}=\{13\}$}

The $x_{-J}^{13}$ are:

$$
\begin{aligned}
& x^{13}=\left(\frac{2}{5}, \frac{\sqrt{3}}{5}\right) \quad x_{-1}^{13}=\left(\frac{3}{4}, \frac{\sqrt{3}}{4}\right) \quad x_{-2}^{13}=\left(0, \frac{\sqrt{3}}{4}\right) \quad x_{-3}^{13}=\left(\frac{3}{8}, \frac{\sqrt{3}}{8}\right) \\
& x_{-12}^{13}=\left(\frac{1}{3}, \frac{\sqrt{3}}{3}\right) \quad x_{-23}^{13}=\left(-\frac{1}{6}, \frac{\sqrt{3}}{6}\right) \quad x_{-13}^{13}=\left(\frac{5}{6}, \frac{\sqrt{3}}{6}\right) \quad x_{-123}^{13}=\left(\frac{1}{4}, \frac{\sqrt{3}}{4}\right) .
\end{aligned}
$$

The 7 inequalities characterizing the feasible payoff set for the lobbies from Proposition 1 are, where

$$
Z\left(x^{13},\{13\}\right)=u_{1}\left(x^{13}\right)+u_{3}\left(x^{13}\right)+\sum_{\ell \in L} v_{\ell}\left(x^{13}\right)=7 / 5
$$




$$
\begin{aligned}
& \text { (1) } \quad B_{1}^{* 13} \leq Z\left(x^{13},\{13\}\right)-Z_{-1}\left(x_{-1}^{13},\{13\}\right)=7 / 5-3=-8 / 5 \\
& \\
& \text { (2) } B_{2}^{* 13} \leq Z\left(x^{13},\{13\}\right)-Z_{-2}\left(x_{-2}^{13},\{13\}\right)=7 / 5-3 / 4=13 / 20 \\
& \text { (3) } B_{3}^{* 13} \leq Z\left(x^{13},\{13\}\right)-Z_{-3}\left(x_{-3}^{13},\{13\}\right)=7 / 5-3 / 4=13 / 20 \\
& \text { (4) } \quad B_{1}^{* 13}+B_{2}^{* 13} \leq Z\left(x^{13},\{13\}\right)-Z_{-12}\left(x_{-12}^{13},\{13\}\right)=7 / 5-4 / 3=1 / 15 \\
& \text { (5) } B_{2}^{* 13}+B_{3}^{* 13} \leq Z\left(x^{13},\{13\}\right)-Z_{-23}\left(x_{-23}^{13},\{13\}\right)=7 / 5-1 / 3=16 / 15 \\
& \text { (6) } B_{1}^{* 13}+B_{3}^{* 13} \leq Z\left(x^{13},\{13\}\right)-Z_{-13}\left(x_{-13}^{13},\{13\}\right)=7 / 5-7 / 3=-14 / 15
\end{aligned}
$$

(7) $B_{1}^{* 13}+B_{2}^{* 13}+B_{3}^{* 13} \leq Z\left(x^{13},\{13\}\right)-Z_{-123}\left(x_{-123}^{13},\{13\}\right)=7 / 5-1 / 2=9 / 10$.

Letting $\bar{B}_{\ell}^{A}$ denote the "candidate" equilibrium constants at which the first three constraints bind, the constraints (4)-(6) at the candidate constants are

$$
\begin{gathered}
1 / 15-\left(\bar{B}_{1}^{13}+\bar{B}_{2}^{13}\right)=1 / 15-(-8 / 5+8 / 5)=\frac{1}{15}(\text { HOLDS }) \\
16 / 15-\left(\bar{B}_{2}^{13}+\bar{B}_{3}^{13}\right)-7 / 5=16 / 15-(-8 / 5+13 / 20)=-\frac{7}{30} \text { (FAILS) } \\
-14 / 15-\left(\bar{B}_{1}^{13}+\bar{B}_{3}^{13}\right)=-14 / 15-(-8 / 5+13 / 20)=\frac{1}{60}(\text { HOLDS }) .
\end{gathered}
$$

Constraint (5) fails at the candidate constants, and the constants of lobbies 2 and 3 must be revised downward collectively by $7 / 30$.

\section{Subgame with Coalition $\mathbf{A}=\{123\}$}

The $x_{-J}^{123}$ are:

$$
\begin{aligned}
& x^{123}=\left(\frac{1}{2}, \frac{1}{2 \sqrt{3}}\right) \quad x_{-1}^{123}=\left(\frac{4}{5}, \frac{\sqrt{3}}{5}\right) \quad x_{-2}^{123}=\left(\frac{1}{5}, \frac{\sqrt{3}}{5}\right) \quad x_{-3}^{123}=\left(\frac{1}{2}, \frac{\sqrt{3}}{10}\right) \\
& x_{-12}^{123}=\left(\frac{1}{2}, \frac{\sqrt{3}}{4}\right) \quad x_{-23}^{123}=\left(\frac{1}{8}, \frac{\sqrt{3}}{8}\right) \quad x_{-13}^{123}=\left(\frac{7}{8}, \frac{\sqrt{3}}{8}\right) \quad x_{-123}^{123}=\left(\frac{1}{2}, \frac{\sqrt{3}}{6}\right) .
\end{aligned}
$$

The 7 inequalities characterizing the feasible payoff set for the lobbies from Proposition 1 are:

$$
\begin{aligned}
& Z\left(x^{123},\{123\}\right)=u_{1}\left(x^{123}\right)+u_{2}\left(x^{123}\right)+u_{3}\left(x^{123}\right)+\sum_{\ell \in L} v_{\ell}\left(x^{123}\right)=2 \\
& \text { (1) } B_{1}^{* 123} \leq Z\left(x^{123},\{123\}\right)-Z_{-1}\left(x_{-1}^{123},\{123\}\right)=2-19 / 5=-9 / 5 \\
& \text { (2) } B_{2}^{* 123} \leq Z\left(x^{123},\{123\}\right)-Z_{-2}\left(x_{-2}^{123},\{123\}\right)=2-4 / 5=6 / 5 \\
& \text { (3) } B_{3}^{* 123} \leq Z\left(x^{123},\{123\}\right)-Z_{-3}\left(x_{-3}^{123},\{123\}\right)=2-7 / 5=3 / 5
\end{aligned}
$$

(4) $\quad B_{1}^{* 123}+B_{2}^{* 123} \leq Z\left(x^{123},\{123\}\right)-Z_{-12}\left(x_{-12}^{123},\{123\}\right)=2-7 / 4=1 / 4$

(5) $\quad B_{2}^{* 123}+B_{3}^{* 123} \leq Z\left(x^{123},\{123\}\right)-Z_{-23}\left(x_{-23}^{123},\{123\}\right)=2-1 / 4=7 / 4$

(6) $B_{1}^{* 123}+B_{3}^{* 123} \leq Z\left(x^{123},\{123\}\right)-Z_{-13}\left(x_{-13}^{123},\{123\}\right)=2-13 / 4=-5 / 4$ 
(7) $B_{1}^{* 123}+B_{2}^{* 123}+B_{3}^{* 123} \leq Z\left(x^{123},\{123\}\right)-Z_{-123}\left(x_{-123}^{123},\{123\}\right)=2-1=1$.

Letting $\bar{B}_{\ell}^{A}$ denote the "candidate" equilibrium constants at which the first three constraints bind, constraints (4)-(6) at the candidate constants are

$$
\begin{gathered}
1 / 4-\left(\bar{B}_{1}^{123}+\bar{B}_{2}^{123}\right)=1 / 4-(-9 / 5+6 / 5)=\frac{17}{20}(\text { HOLDS }) \\
7 / 4-\left(\bar{B}_{2}^{123}+\bar{B}_{3}^{123}\right)-7 / 5=7 / 4-(6 / 5+3 / 5)=-\frac{1}{20}(\text { FAILS }) \\
-5 / 4-\left(\bar{B}_{1}^{123}+\bar{B}_{3}^{123}\right)=-5 / 4-(-9 / 5+3 / 5)=-\frac{1}{20}(\text { FAILS }) .
\end{gathered}
$$

Constraints (5) and (6) fail at the candidate constants, and the constants must be revised downward collectively by $1 / 20$. 


\section{References}

[1] Axelrod, Robert M. 1970. Conflict of Interest: A Theory of Divergent Goals with Applications to Politics. Markham: Chicago.

[2] Baron, David P. 2006. "Competitive Lobbying and Supermajorities in a Majority-Rule Institution." Scandinavian Journal of Economics. 108: 607-642.

[3] Baron, David P. and Daniel Diermeier. 2001. "Elections, Governments, and Parliaments in Proportional Representation Systems." Quarterly Journal of Economics. 115: 933-967.

[4] Bernheim, B. Douglas and Michael D. Whinston. 1986a. "Menu Auctions, Resource Allocation, and Economic Influence." Quarterly Journal of Economics. 101, 1-31.

[5] Bernheim, B. Douglas and Michael D. Whinston. 1986b. "Common Agency." Econometrica. 54: 923-942.

[6] Debus, Marc. 2009. "Pre-electoral commitments and government formation." Public Choice. 138: 45-64.

[7] Dekel, Eddie, Matthew O. Jackson, and Asher Wolinsky. 2007. "Vote Buying: Legislatures and Lobbying." Quarterly Journal of Political Science. (forthcoming).

[8] Diermeier, Daniel, Hulya Eraslan, and Antonio Merlo. 2002. "Coalition governments and comparative constitutional design." European Economic Review. 46: 893-907.

[9] Diermeier, Daniel, Hulya Eraslan, and Antonio Merlo. 2003. "A Structural Model of Government Formation." Econometrica. 71: 27-70.

[10] Felli, Leonardo and Antonio Merlo. 2006. "Endogenous Lobbying." Journal of the European Economic Association. 4: 180-215.

[11] Golder, Sona N. 2005. "Pre-electoral Coalitions in Comparative Perspective." Electoral Studies. 24: 643-663.

[12] Golder, Sona N. 2006. "Pre-electoral Coalition Formation in Parliamentary Democracies." British Journal of Political Science. 36: 193-212.

[13] Grofman, Bernard. 1982. "A Dynamic Model of Protocoalition Formation in Idelological N-Space." Behavioral Science. 27: 77-90.

[14] Groseclose, Tim and James M. Snyder. 1996. "Buying Supermajorities." American Political Science Review, 90 (June): 303-315. 
[15] Grossman, Gene M. and Elhanan Helpman. 1994. "Protection for Sale." American Economic Review. 84 (September): 833-850.

[16] Helpman, Elhanan and Torsten Persson. 2001. "Lobbying and Legislative Bargaining." Advances in Economic Analysis 83 Policy. 1: Article 3.

[17] Laver, Michael and Norman Schofield. 1991. Multiparty Governement: The Politics of Coalition in Europe. Oxford University Press; Oxford, UK.

[18] Laver, Michael. 1992. "Using Cluster Analysis to Model Coalition Formation." in Michael Laver and Ian Budge, eds. Party and Coalition Policy in Western Europe. New York, NY: St. Martin's Press.

[19] Martin, Lanny W. and Randolph T. Stevenson. 2001. "Government Formation in Parliamentary Democracies." American Journal of Political Science. 45: 33-50.

[20] Prat, Andrea and Aldo Rustichini. 2003. "Games Played Through Agents." Econometrica. 71: 989-1026.

[21] Segal, Ilya. 1999. "Contracting with Externalities." Quarterly Journal of Economics. 104: 337-388.

[22] Seidmann, Daniel J., Eyal Winter, and Elan Pavlov. 2007. "The formateur's role in government formation." Economic Theory. 31:427-445.

[23] Strom, Kaare and W. Muller. 1999. "The Keys to Togetherness." Journal of Legislative Studies. 5: 255-282. 


\section{Figure 1 - Coalition Selection}

$1 /|A|$ Share to Formateur

$A^{*}=\{12\}$

$A^{*}=\{123\}$ 


\section{Figure 2 - Coalition Selection All to Formateur}

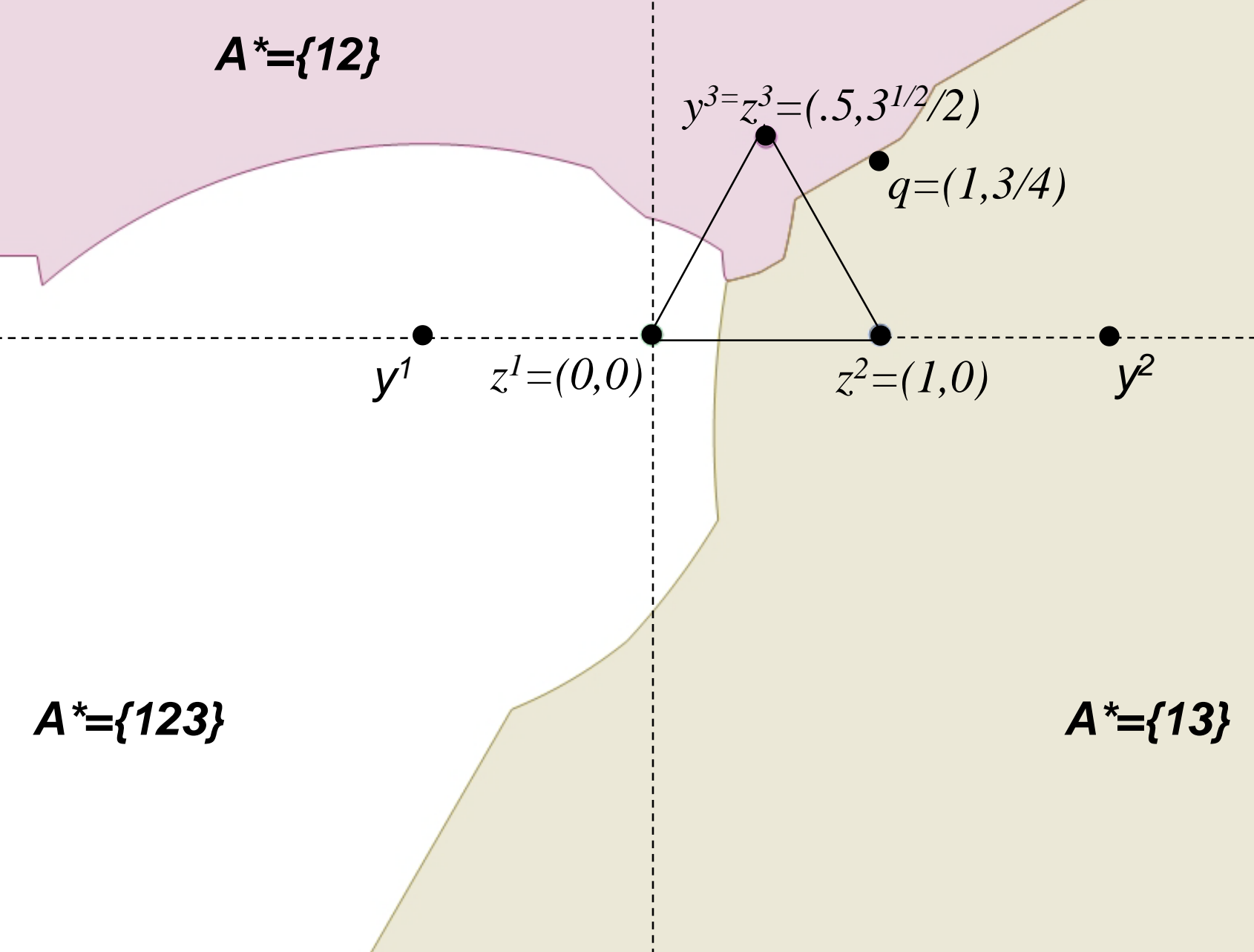




\section{Figure 3 - Coalition Selection None to Formateur}

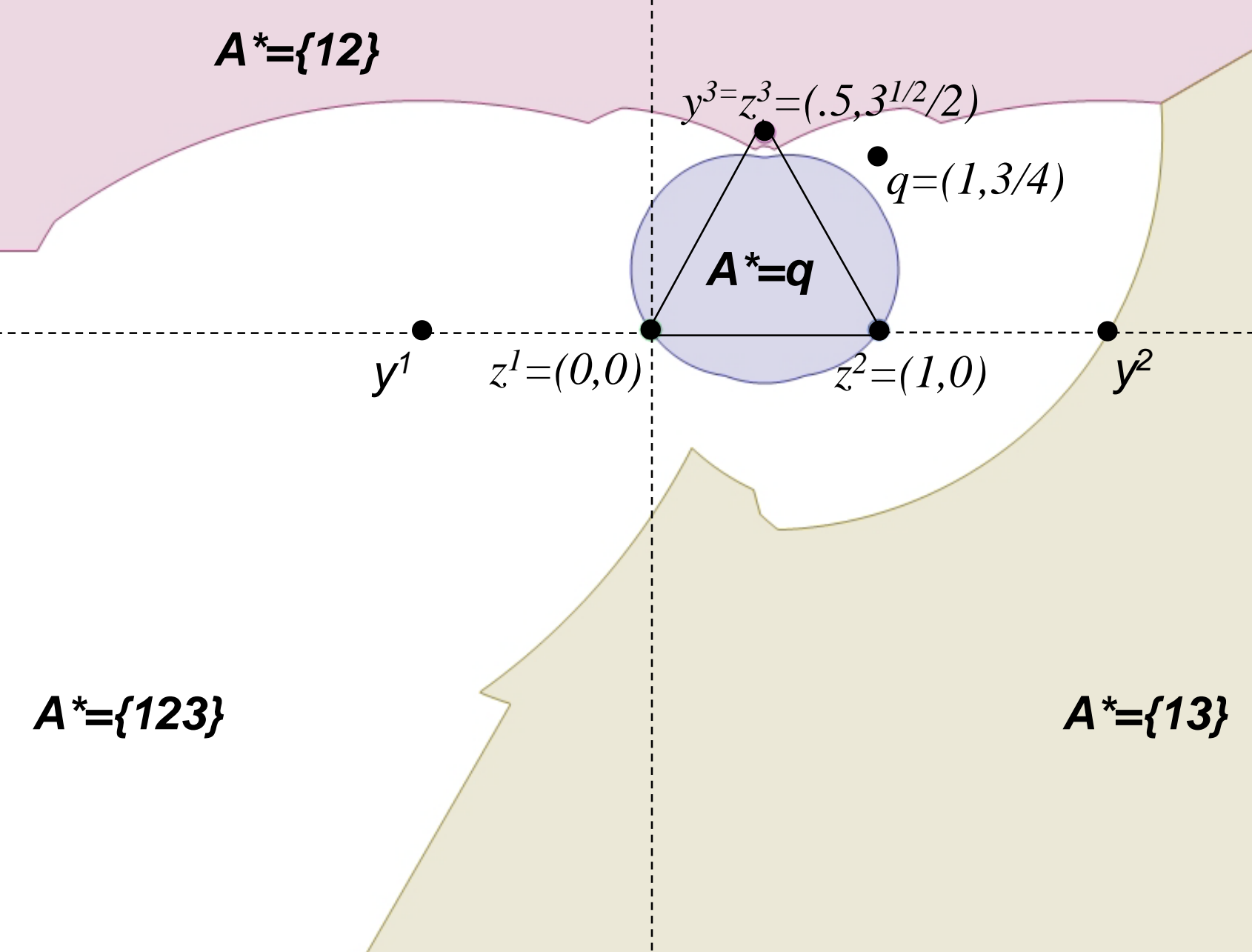




\section{Figure 4 - Formateur Preferences 1/|A| Share to Formateur}

$A^{*}=\{12\}$

$A^{*}=\{123\}$

$A^{*}=\{13\}$ 


\section{Figure 5 - Formateur Preferences All to Formateur}

$A^{*}=\{12\}$

$$
A^{*}=\{123\}
$$

$$
y^{3=} z^{3}=\left(.5,3^{1 / 2} / 2\right)
$$$$
q=(1,3 / 4)
$$

$$
y^{1} \quad z^{1}=(0,0)
$$

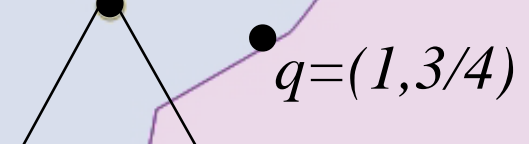




\section{Figure 6 - Formateur Preferences}

\section{None to Formateur}

$A^{*}=\{12\}$

$A^{*}=\{123\}$

$y^{3=} z^{3}=\left(.5,3^{1 / 2} / 2\right)$

$y^{1} \quad z^{1}=(0,0)$

$\bullet_{q}=(1,3 / 4)$

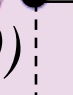

$z^{2}=(1,0)$

$y^{2}$

$A^{*}=\{13\}$ 


\section{Figure 7 - Coalition Selection, Extreme Lobby 1/|A| Share to Formateur}

$A^{*}=\{12\}$

- $y^{3}=(1 / 2,2)$

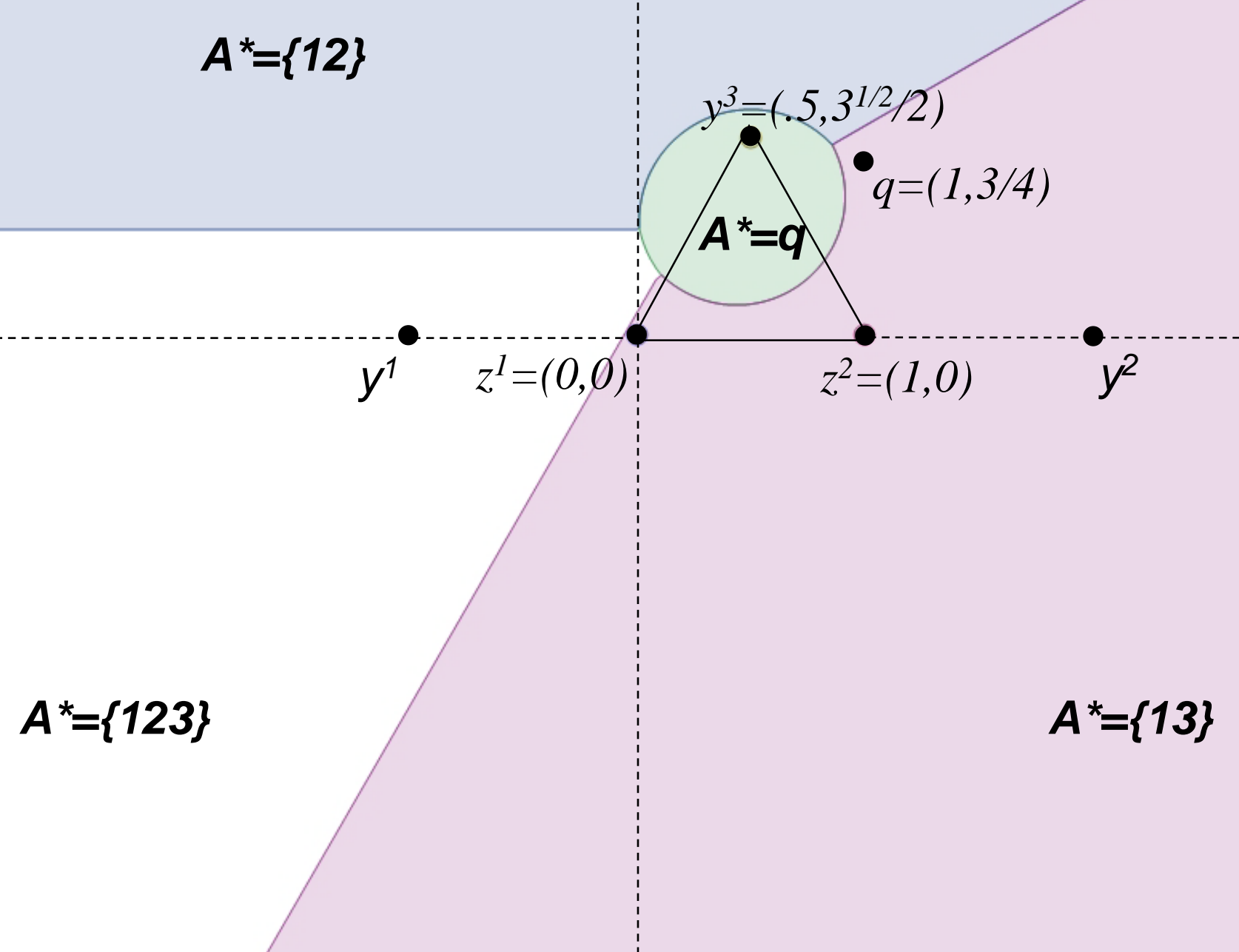




\section{Figure 8 - Coalition Selection, Extreme Lobby All to Formateur}

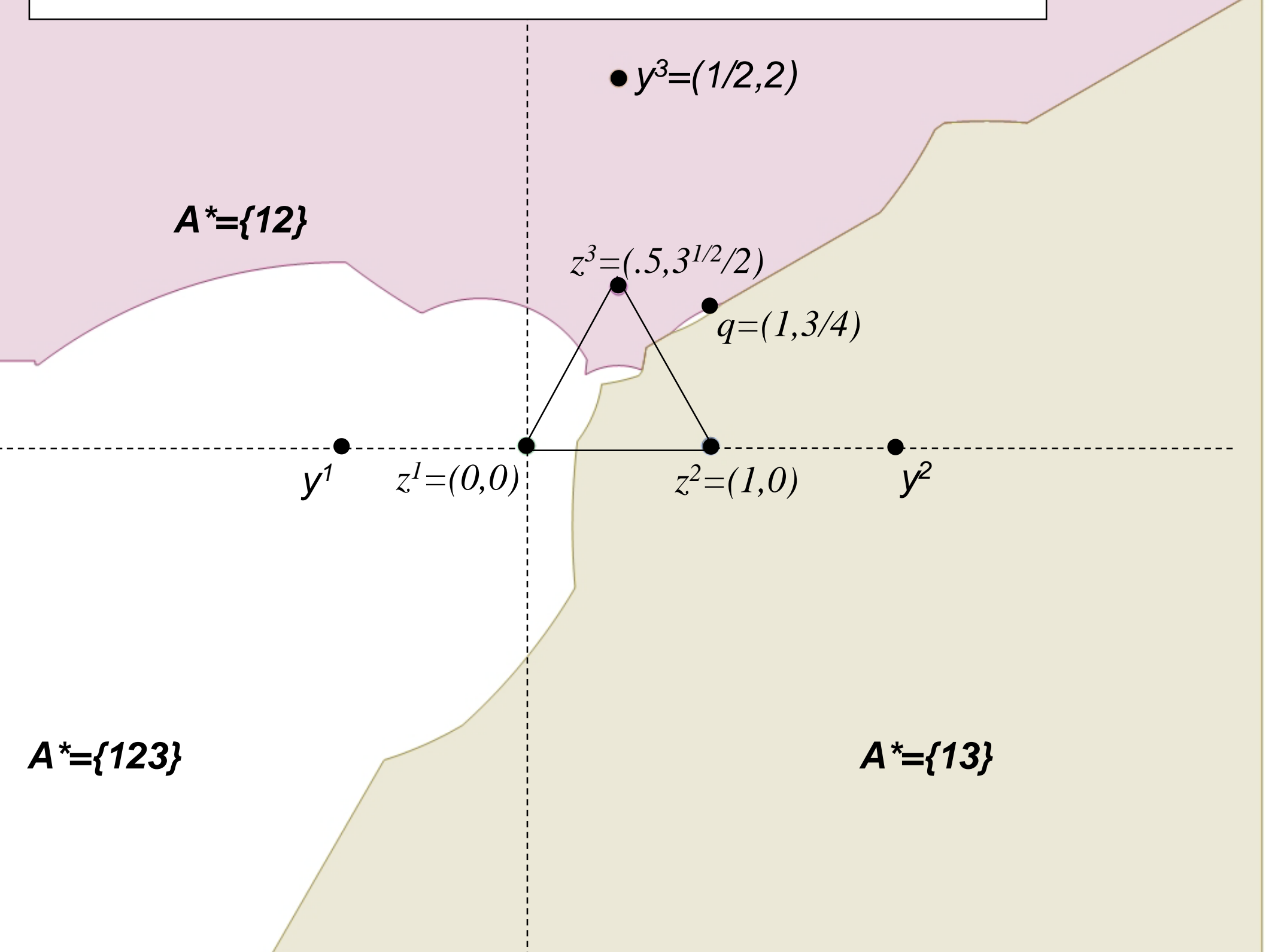




\section{Figure 9 - Coalition Selection, Extreme Lobby \\ None to Formateur}

- $y^{3}=(1 / 2,2)$

$A^{*}=\{123\}$

\section{$A^{*}=q$}

$y^{1} \quad z^{1}=(0,0)$

$A^{*}=\{12\}$ 
Figure 10

\section{Equilibrium Coalitions}

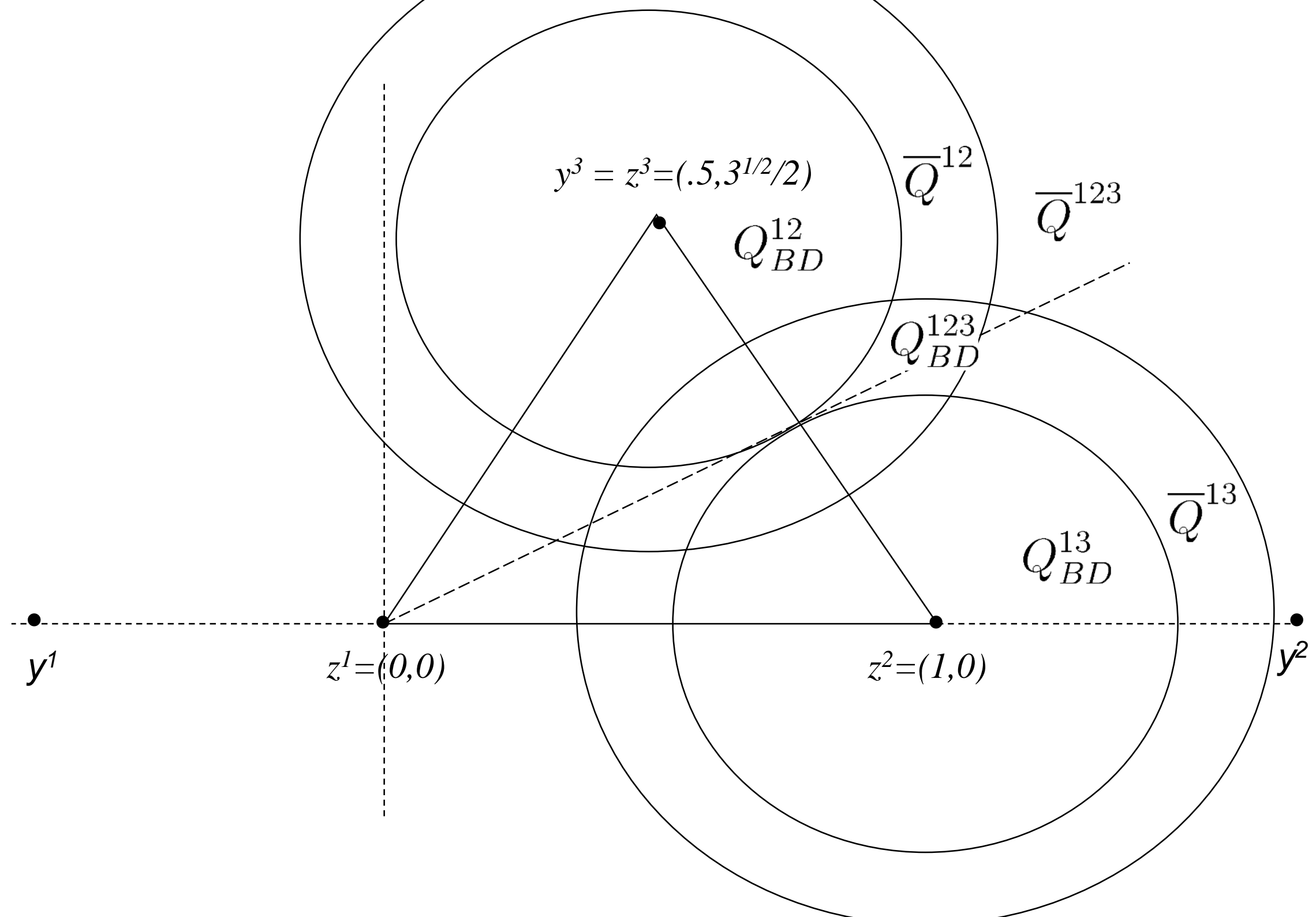

